\title{
Comparison of numerical simulation to existing experimental data involving downwash wake reduction for the V-22 Osprey
}

\author{
Brian O'Hara \\ West Virginia University
}

Follow this and additional works at: https://researchrepository.wvu.edu/etd

\section{Recommended Citation}

O'Hara, Brian, "Comparison of numerical simulation to existing experimental data involving downwash wake reduction for the V-22 Osprey" (2005). Graduate Theses, Dissertations, and Problem Reports. 4181. https://researchrepository.wvu.edu/etd/4181

This Thesis is protected by copyright and/or related rights. It has been brought to you by the The Research Repository @ WVU with permission from the rights-holder(s). You are free to use this Thesis in any way that is permitted by the copyright and related rights legislation that applies to your use. For other uses you must obtain permission from the rights-holder(s) directly, unless additional rights are indicated by a Creative Commons license in the record and/ or on the work itself. This Thesis has been accepted for inclusion in WVU Graduate Theses, Dissertations, and Problem Reports collection by an authorized administrator of The Research Repository @ WVU. For more information, please contact researchrepository@mail.wvu.edu. 


\title{
Comparison of Numerical Simulation to Existing Experimental Data involving Downwash Wake Reduction for the V-22 Osprey
}

\author{
Brian O’Hara \\ Thesis Submitted to the \\ College of Engineering and Mineral Resources \\ at West Virginia University \\ in partial fulfillment of the requirements \\ for the degree of \\ Master of Science \\ in \\ Aerospace Engineering \\ James Smith, Ph.D., Chair \\ Wade Huebsch, Ph.D. \\ Jacky Prucz, Ph.D. \\ Department of Mechanical and Aerospace Engineering \\ Morgantown, West Virginia \\ 2005
}

Keywords: Circulation Control, Blowing Slot, CFD 


\begin{abstract}
Comparison of Numerical Simulation to Existing Experimental Data involving

Downwash Wake Reduction for the V-22 Osprey

By Brian O’Hara
\end{abstract}

It is of interest to develop numerical techniques to simulate the implementation of blowing slots on a V-22 Osprey airfoil in order to alleviate downwash. In order to develop these techniques, two separate experiments were simulated and the numerical results were compared with the experimental data. The first experiment used in comparison was performed by Fort F. Felker at the NASA's AMES Research Center in 1990. The second experiment was done by Chad Riba and Gerald M. Angle at West Virginia University in 2003.

The commercially available RNG k-e turbulence model with enhanced wall treatment found in Fluent 6.1 was used to solve the flows. The solutions were then compared to experimental data. Good correlation between the computational and experimental data was found. Similar to what was found in the WVU experiment, download on the wing from the rotors while the aircraft is operating in vertical take-off and landing mode was found to be reduced by the blowing slots. The difference between the percent download reduction in the WVU experiment and the computational model was found to be approximately $3 \%$. 


\section{Table of Contents}

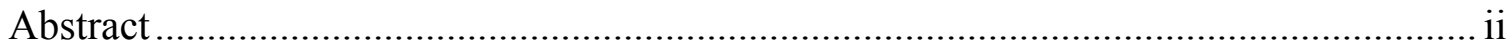

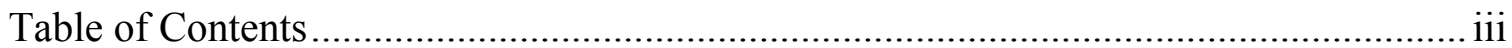

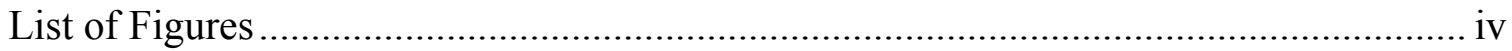

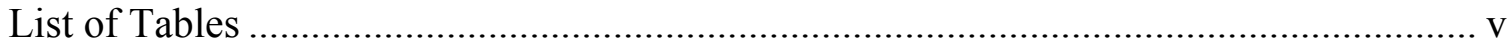

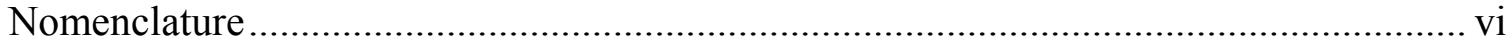

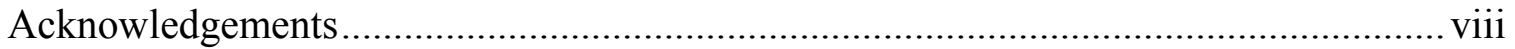

Chapter 1.0: Introduction ...................................................................................... 1

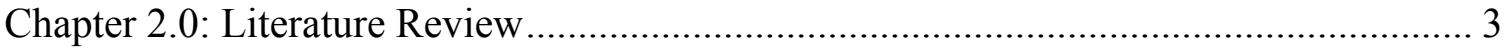

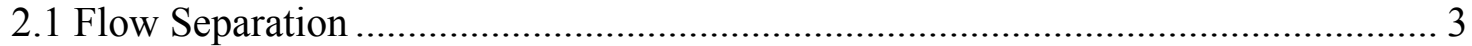

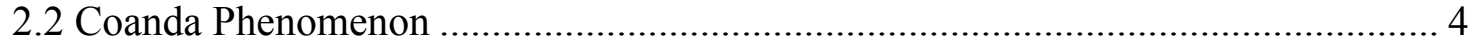

2.3 Circulation Control Airfoils............................................................................ 4

2.4 Active Circulation Control.................................................................................. 5

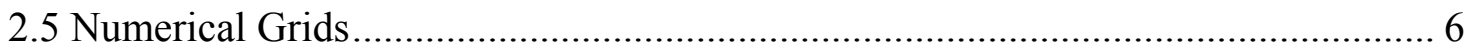

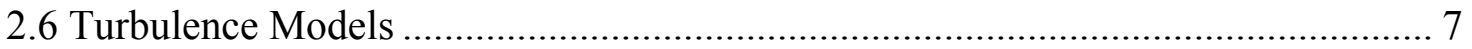

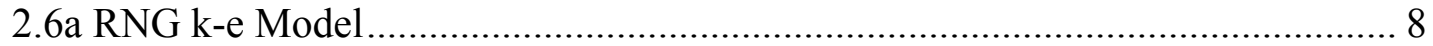

2.6b Reynolds Stress Model (RSM) .................................................................. 9

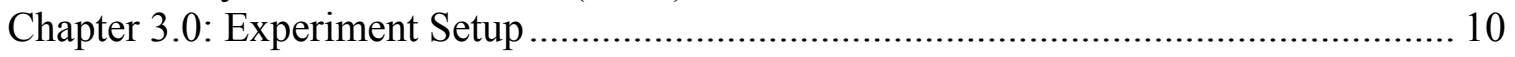

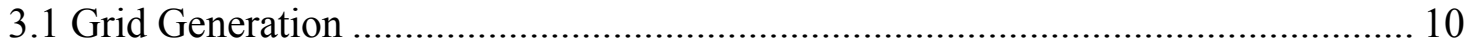

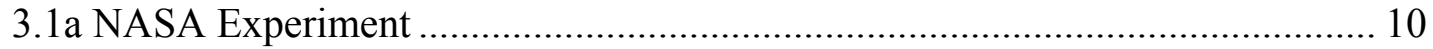

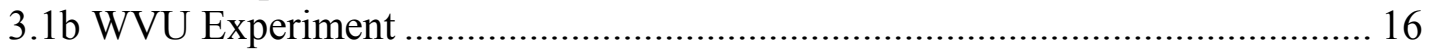

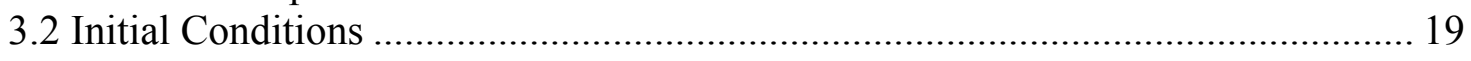

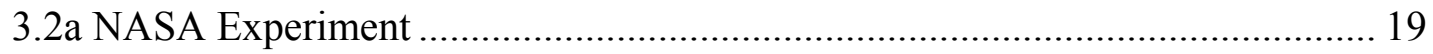

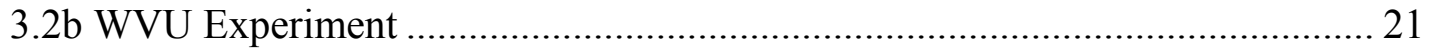

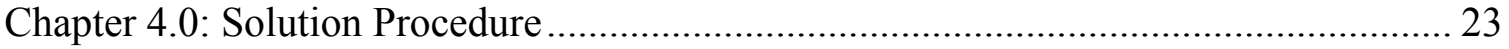

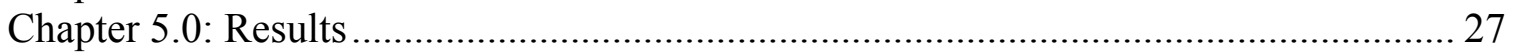

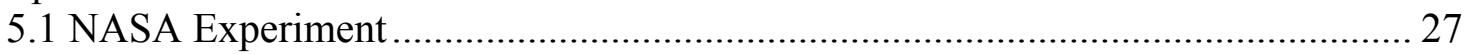

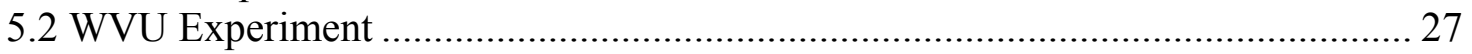

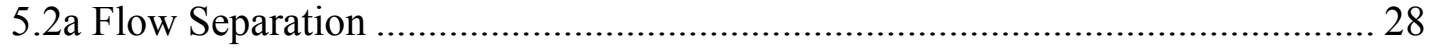

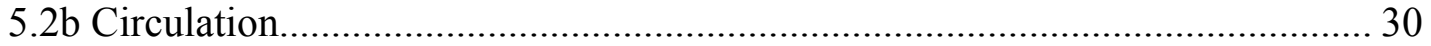

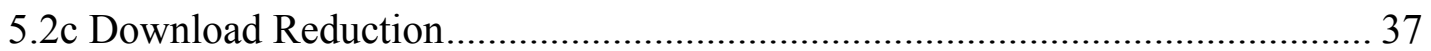

Chapter 6.0: Conclusions and Recommendations ..................................................... 39

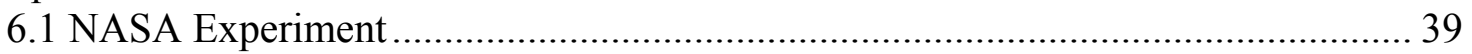

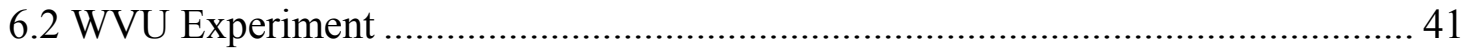

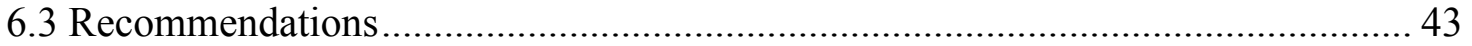

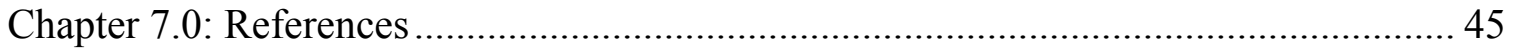

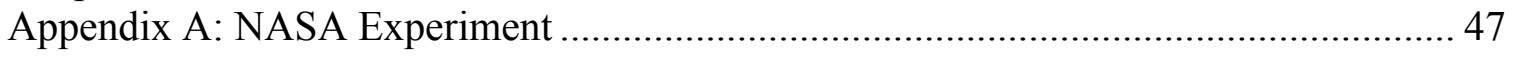

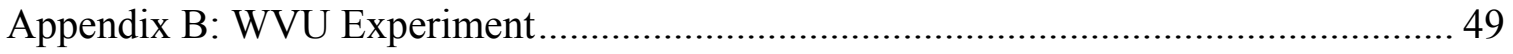




\section{List of Figures}

Figure 1.1: Downwash from Rotors in Vertical Take Off and Landing Configuration ..... 1 Figure 3.1: Placement of Computational Grid within Felker Experimental Setup.......... 12 Figure 3.2: Felker Experiment: Overall View of Boundaries for Computational Grid .... 12 Figure 3.3: Left: Felker Experiment: Experimental Wing Configuration, Right:

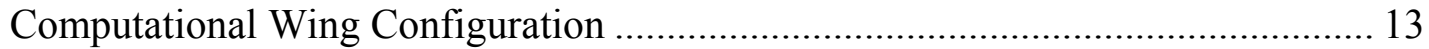

Figure 3.4: Felker Experiment: Computational Grid close to the Airfoil........................ 15

Figure 3.5: WVU Experiment: Overall View of Boundaries for Computational Grid..... 17

Figure 3.6: WVU Experiment: View of entire Computational Grid ............................. 18

Figure 3.7: WVU Experiment: Computational Grid close to Blowing Slot ..................... 19

Figure 4.1: Comparison of RNG k-e and RSM Turbulence Models ............................. 25

Figure 5.1: Comparison of Computational and Experimental Results for Fort Felker's

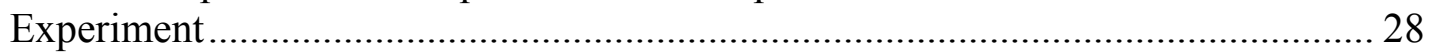

Figure 5.2: Separation Point for Various Blowing Slot Velocities.................................. 29

Figure 5.3: Contours of Total Pressure (lb/ft2), Blowing Slot Velocity: 0 fps................ 31

Figure 5.4: Contours of Total Pressure (lb/ft2), Blowing Slot Velocity: $10 \mathrm{fps}$.............. 31

Figure 5.5: Contours of Total Pressure (lb/ft2), Blowing Slot Velocity: $60 \mathrm{fps}$.............. 32

Figure 5.6: Contours of Total Pressure (lb/ft2), Blowing Slot Velocity: 130 fps............. 32

Figure 5.7: Contours of Total Pressure (lb/ft2), Blowing Slot Velocity: $200 \mathrm{fps}$............. 33

Figure 5.8: Pathlines colored by Particle ID near the Leading Edge.............................. 34

Figure 5.9: Pathlines colored by Particle ID near the Trailing Edge .............................. 34

Figure 5.10: Contours of Vorticity Magnitude around the Airfoil in 1/s........................ 35

Figure 5.11: Vector Plot near the Leading Edge..................................................... 36

Figure 5.12: Vector Plot near the Trailing Edge......................................................... 36

Figure 5.13: Comparison of Download between Experimental and Computational

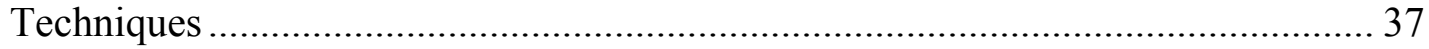

Figure 5.14: Comparison of the Percent Download Reduction between Experimental and

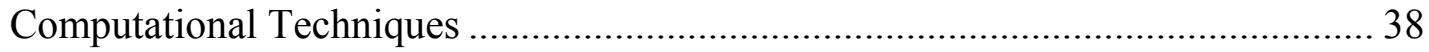

Figure 6.1: Leading Edge Velocity Vectors for NASA Experiment (fps)...................... 41

Figure B.1: Leading Edge Blowing Slot Velocity Vectors (fps), Blowing Slot Velocity:

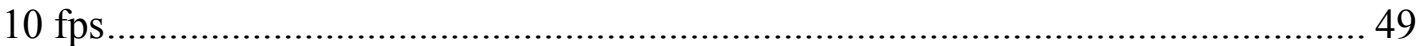

Figure B.2: Leading Edge Blowing Slot Velocity Vectors (fps), Blowing Slot Velocity:

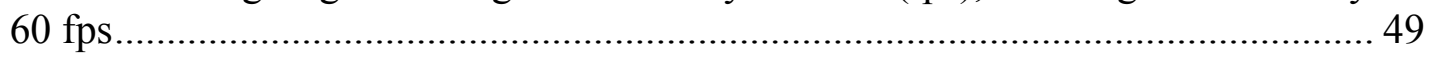

Figure B.3: Leading Edge Blowing Slot Velocity Vectors (fps), Blowing Slot Velocity:

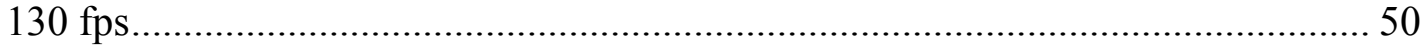

Figure B.4: Leading Edge Blowing Slot Velocity Vectors (fps), Blowing Slot Velocity: $200 \mathrm{fps}$.....

Figure B.5: Velocity Vectors Around Airfoil (fps), Blowing Slot Velocity: 0 fps ......... 51

Figure B.6: Velocity Vectors Around Airfoil (fps), Blowing Slot Velocity: $10 \mathrm{fps}$....... 51

Figure B.7: Velocity Vectors Around Airfoil (fps), Blowing Slot Velocity: $60 \mathrm{fps}$........ 52

Figure B.8: Velocity Vectors Around Airfoil (fps), Blowing Slot Velocity: $130 \mathrm{fps}$...... 52

Figure B.9: Velocity Vectors Around Airfoil (fps), Blowing Slot Velocity: $200 \mathrm{fps}$...... 53 


\section{List of Tables}

Table 3.1: Experimental Slot Pressure and Corresponding Momentum Coefficient........ 22

Table 3.2: Computational Slot Velocity and Corresponding Momentum Coefficient ..... 22

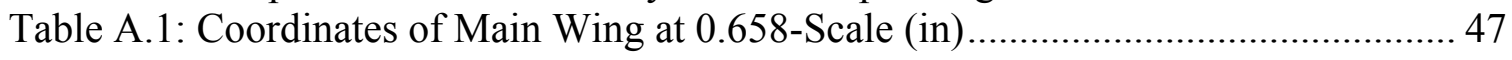

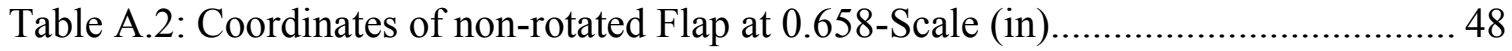

Table A.3: Coordinates of Flap Cove at 0.658 -Scale (in) .......................................... 48 


\section{Nomenclature}

$\begin{array}{ll}\text { A } & \text { Area }\left(\mathrm{ft}^{2}\right) \\ \text { c } & \text { Chord Length (ft) } \\ \text { b } & \text { Wing Span (ft) } \\ \text { FM } & \text { Figure of Merit } \\ \text { G } & \text { Generation of Turbulent Kinetic Energy }\left(\mathrm{lbm} / \mathrm{ft}^{-\mathrm{s}^{3}}\right) \\ \mathrm{h} & \text { Slot Height }(\mathrm{ft}) \\ \mathrm{k} & \text { Turbulent Kinetic Energy }\left(\mathrm{lbm} / \mathrm{ft}^{3} \mathrm{~s}^{3}\right) \\ \dot{m} & \text { Mass Flow Rate }(\mathrm{lbm} / \mathrm{s}) \\ \mathrm{S} & \text { Source Term }\left(\mathrm{lbm} / \mathrm{ft}-\mathrm{s}^{3}\right) \\ \mathrm{t} & \text { Time (sec) } \\ \mathrm{T} & \text { Thrust }(\mathrm{lbf}) \\ \mathrm{u} & \text { Mean Velocity }(\mathrm{ft} / \mathrm{s}) \\ \mathrm{V} & \text { Velocity (ft/s) } \\ \mathrm{x} & \text { Independent Variable }(\mathrm{ft}) \\ \mathrm{Y} & \text { Dilatation Dissipation }\left(\mathrm{lbm} / \mathrm{ft}-\mathrm{s}^{3}\right)\end{array}$

\section{Symbols}

$\alpha \quad$ Inverse Effective Prandtl Number

$\delta_{i j} \quad$ Kronecker Delta

d Partial Derivative

$\varepsilon \quad$ Turbulent Kinetic Energy Dissipation Rate $\left(\mathrm{ft}^{2} / \mathrm{s}^{3}\right)$ 


$\begin{array}{ll}\mu & \text { Viscosity }(\mathrm{lbm} / \mathrm{ft}-\mathrm{s}) \\ \rho & \text { Density }\left(\text { slug/ } / \mathrm{ft}^{3}\right) \\ \Omega & \text { Mean Rate-of-Rotation }\end{array}$

\section{Subscripts}

$\begin{array}{ll}\text { act } & \text { actual... } \\ \text { e } & \text {... due to Buoyancy } \\ \text { eff } & \text { Exit } \\ \mathrm{i}, \mathrm{j}, \mathrm{k} & \text { Effective ... } \\ \text { ideal } & \ldots \text { for ideal rotor } \\ \text { ind } & \text { Induced ... } \\ \mathrm{j} & \ldots \text { in the jet } \\ \mathrm{k} & \ldots \text { due to Mean Velocity Gradients } \\ \mathrm{M} & \text {... due to Turbulent Mach Number } \\ \mathrm{t} & \text { Turbulent ... } \\ 0 & \text { Initial } \\ \infty & \text { Freestream ... }\end{array}$




\section{Acknowledgements}

The author wishes to thank the Center for Industrial Research Applications in conjuncture with West Virginia University for the opportunity to work on this project. Special thanks go to Dr. Wade Huebsch and Gerald Angle II for answering numerous questions and providing guidance. Thanks also go to Dr. James Smith for his overall guidance and encouragement.

Finally, the author would like to thank his family for the wealth of encouragement and support they have provided. 


\section{Chapter 1.0: Introduction}

The main purpose of the V-22 Osprey's design is to give it special capabilities and flight characteristics. Specifically the design lends itself to higher payloads, better range, and vertical take-off and landing. Yet this design does come with some drawbacks and limitations. When the V-22 Osprey is flying in the vertical take off and landing configuration, there is considerable downwash from the rotor blades onto the wings. Figure 1.1 shows the V-22 in vertical take-off and landing mode along with some illustration that shows where the downwash is impinging upon the wings. Obviously, having the wing in the way of the rotor downwash is not ideal. Negative effects are created that can have a penalty on the aircraft's performance.

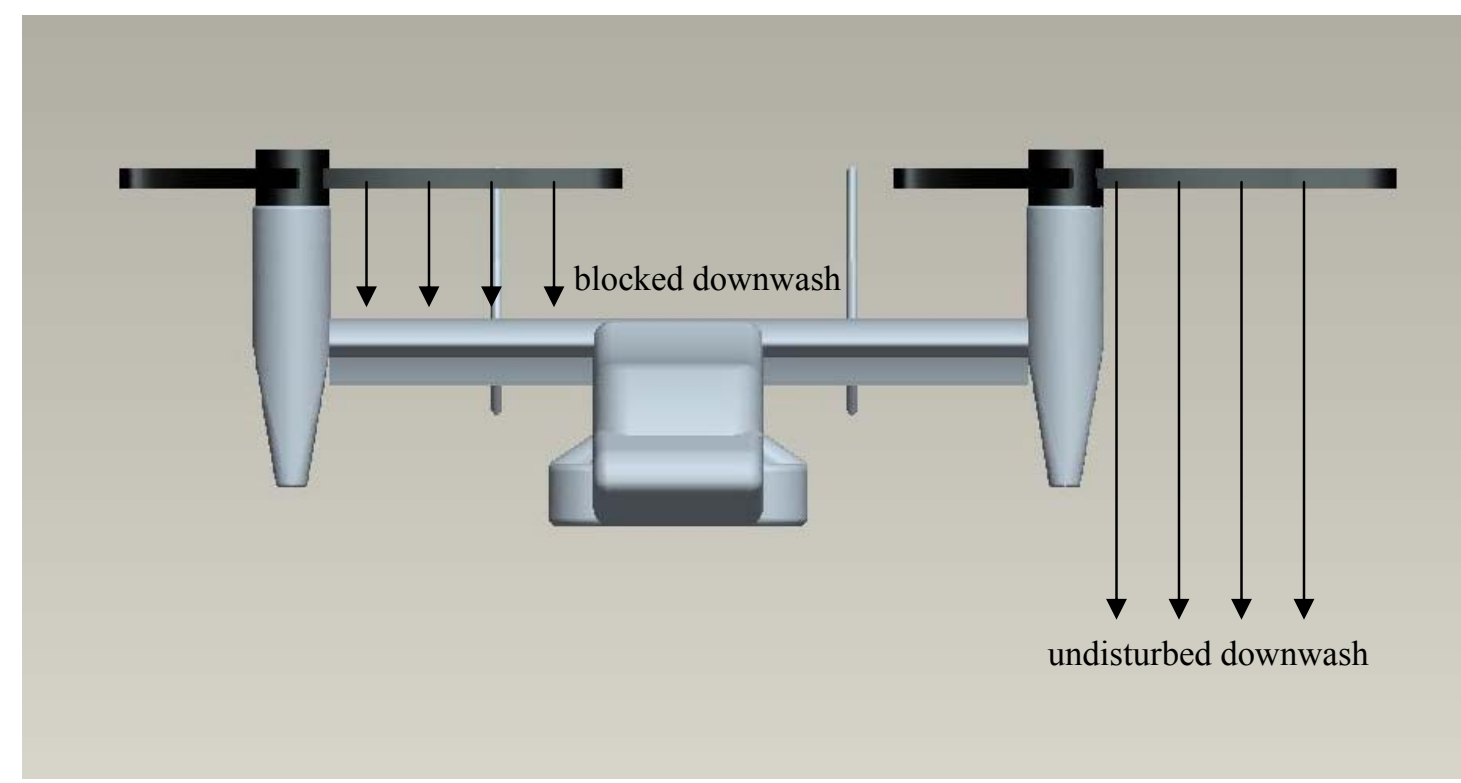

Figure 1.1: Downwash from Rotors in Vertical Take Off and Landing Configuration With the design of the V-22 already in place, the options are limited for design changes that could potentially help the downwash problem. These options include, but are not limited to, changing the geometry of the wing, changing the flap configurations, and adding other components such as blowing slots to effectively change the 
aerodynamics of the wing. Since the wing and flaps have already been optimized for the V-22 in horizontal flight, using blowing slots could be the best option. In an effort to alleviate some of the negative effects associated with the downwash, blowing slots were experimentally and computationally placed on the wings.

The overall objective of this research was to develop computational methods useful in testing active circulation control, via blowing slots, on the V-22 Osprey. As an initial test of the numerical model, the computational methods were used to simulate the 1990 experiment performed by Fort F. Felker at the NASA's AMES Research Center [1]. The second phase used the methods developed during the first phase to model Gerald M. Angle's 2003 experiment at West Virginia University [2]. For clarification, Felker's experiment is referred to as the NASA experiment throughout the paper and Angle's experiment is called the WVU experiment.

Direct comparisons between the experimental data and the computational results were made. The computational results were also reviewed further to make sure the flow phenomenon appeared to be physically possible. This was done using velocity vector, pressure contour, vorticity contour, and pathline plots. 


\section{Chapter 2.0: Literature Review}

This section examines previous work that has been done in the area of active circulation control. In the past there has been a large amount of experimental work done and more recently there has been a growing amount of numerical work.

\subsection{Flow Separation}

As flow moves along any surface it is subject to the no slip condition. The no slip condition creates a boundary layer near the surface, which has no velocity at the wall and rapidly increases in velocity away from the wall. In the case of low viscosity fluids such as air, the boundary layer is typically very thin. When the boundary layer moves away from the surface and flow reversal occurs next to the surface, flow separation occurs. Flow separation is very dependant on the pressures inside and surrounding the boundary layer.

A classic example of flow separation is flow around a cylinder [3]. According to Bernoulli's equation, as frictionless fluid moves around the cylinder it is subjected to high pressure at the leading edge, low pressure at 90 degrees around the cylinder, and high pressure at the trailing edge. In real fluid flow, fluid that is not frictionless, the boundary layer around the leading half of the cylinder is subjected to a favorable pressure gradient so it remains attached. The boundary layer does not stay attached to the trailing edge because of the adverse pressure gradient that it faces. As the fluid in the boundary layer moves around the cylinder it is subjected to larger frictional forces which create heat and take away kinetic energy. When this low energy fluid meets the higher pressure on the trailing side of the cylinder, external pressures begin to dominate the flow and 
make it move in the opposite direction. This first occurs right next to the surface since this is the slowest moving fluid.

The actual separation point is of course very dependant on the type of flow and the Reynolds number. Typically separation occurs around blunt bodies. Along with separation, vortex formation occurs along with a turbulent wake. Large energy losses are associated with a turbulent wake, so avoiding flow separation is generally desirable.

\subsection{Coanda Phenomenon}

The Coanda effect is characterized by the tendency of a jet of fluid to follow a convex curved surface. The jet attempts to reach a balance between the normal pressure gradient and inertial forces as it travels around the surface. As long as the balance is maintained, the jet will remained attached to the surface.

As the jet moves along the surface it also entrains fluid from its surroundings. Since this entrained fluid has lower momentum, it causes the jet to slow down and expand. Eventually the viscous forces become more dominate and the jet separates from the surface [4]. Higher momentum jets remain attached to the surface longer as they can better overcome the influx of lower momentum fluid from the surroundings [5]. It is possible for a Coanda jet to stay attached to a convex surface for a prolonged distance; up to 180 degrees [6].

\subsection{Circulation Control Airfoils}

Typical circulation control airfoils use the Coanda effect to increase lift. This type of airfoil has a rounded trailing edge over which a tangentially blown jet of fluid is introduced. The jet of air stays attached to the surface longer, which increases circulation, which provides lift augmentation [7]. The blowing slot's output can then be 
used as a means to control lift for lifting airfoils [8]. The purpose of this type of airfoil is to increase lift to weight ratios making it possible to maneuver at slower speeds [4]. Increases in lift can be up to 10 times that of a normal flap system [9].

\subsection{Active Circulation Control}

Flow control, when used effectively, has the potential to be extremely beneficial. Through flow control the use of transition delay, lift enhancement, drag reduction, turbulence augmentation, noise suppression, and separation postponement have been investigated for various flow regimes [10]. Active flow control has become more prominent as efforts to make modern craft more efficient and maneuverable have increased. Blowing slots are one type of flow control device currently under investigation in the research community.

Blowing slots are not only used for augmenting lifting surfaces. It is especially of interest to the U.S. Navy which uses aircraft, ships, and submarines. These craft can sometimes benefit from increased maneuverability at slow speeds [11]. These scenarios are similar to the downwash over a V-22 airfoil. Performance should be able to be improved with blowing slots by moving separation points, increasing circulation, and reducing drag. This happens when the separation point is moved in such a way that the size of the wake is reduced. The amount which the wake can be reduced is dependant on a few factors, including slot width, blowing stagnation pressure/ blowing velocity, and radius of curvature [2].

Tests have also been conducted using pulsed blowing. The idea behind using pulsed blowing is to get a similar effect as continuous blowing but with less mass flow and thus less wasted energy. If the blowing is pulsed at the correct frequencies it has 
been found to be very effective. Because of the time lag in the flow mixing, an essentially continuous entrainment of air can be obtained [12]. In fact, as a mechanism for increasing lift coefficient, pulsed blowing has been found to be up to four times as effective as continuous blowing [13].

While active circulation control airfoils show good potential, they do come with penalties. Short takeoff and landing aircraft create a high workload for the pilot. This could possibly be avoided with advances in fly-by-wire technology. Other problems include the extra weight and power consumption associated with the required blowing power for circulation control devices [14].

\subsection{Numerical Grids}

Numerical grids developed for circulation control airfoils equipped with blowing slots mostly follow a similar design. The most critical area is around the blowing slot and immediately downstream of the blowing slot. This area must always include a higher density of grid points to accurately model the flow physics in this region. References 5 , $6,7,8,9,11$, and 15 , all show computational grids with very compact cells near the blowing slots. Typically the grid yields a $\mathrm{y}^{+}$value of around 1 next to the surface. This is especially critical next to the surfaces that have a tangentially blown jet. All of the above references also use two-dimensional grids. The most complicated grid was created by Ferguson, et al. [15] which used two separate blowing slots on the trailing edge to further enhance the effects associated with the Coanda effect. This grid actually features two separate areas of densely packed grid points surrounding the blowing slots. Good results were obtained with this grid and this further demonstrates the importance of having a refined grid. 
To create a blowing slot in an experiment, a plenum needs to be used in order to create uniform blowing across the slot. Modeling of a plenum in a computational domain can be difficult. It requires many extra grid points and makes the blowing slot coefficient difficult to match to the experiment. More importantly it requires more runtime to come up with a solution. Baker, W.J. found that modeling the plenum was not necessary [9]. Accurate results could be obtained without modeling the plenum. Runtimes dropped by a factor of four when the blowing slot was modeled at the orifice.

\subsection{Turbulence Models}

In industry and research there are a wide range of different numerical models which can be used for a wide range of applications. Some of these models are simple and can be used to solve laminar flows. In reality, there aren't many instances of purely laminar flow, so the rest of the models have been developed to solve more complex flows. These so called turbulence models use simplified versions of the famous NavierStokes equations.

A full analytical solution of the Navier-Stokes equations is currently impossible. Direct numerical simulation which digitally solves all of the Navier-Stokes equations is possible but very time expensive. In order to quickly and efficiently solve the randomly fluctuating properties of turbulent flow, the Navier-Stokes equations must be timeaveraged or Reynolds-averaged and discretized for use on a digital computer. Because computer resources are usually limited, the numerical models vary in complexity and also accuracy. Research has been conducted to test how well the turbulence models simulate blowing slots. 
J.F. Slomski compared the use of the RSM, k-e, and realizable k-e turbulence models [6]. It was found that the RSM consistently provided the best prediction of flow separation around the trailing edge of a circulation control airfoil. The k-e and realizable k-e models also did a good job of predicting lift coefficients and flow separation, but not for high blowing slot coefficients. When the blowing slot coefficient was increased above 0.1 the k-e models rapidly decreased in accuracy while the RSM continued to predict proper circulation. Similarly, Swanson, R.C. found that blowing slot coefficients above 0.226 resulted in poor numerical prediction for SST and k-enstrophy models [7].

Lower order models such as the Baldwin-Lomax and SA, were found to be accurate with the use of a proper curvature effect coefficients $[7,16]$.

The majority of the previous experiments looked into the two equation models. Two equation models provided accurate results for lower blowing slot coefficients [6, 9]. They also don't require curvature modeling like the one equation models [16] and save on computational expenses when compared to the RSM model.

The next two sections briefly describe the two turbulence models that were used during this research. Reasons for why each model was used are explained in Chapter 4.

\section{6a RNG k-e Model}

The k-e model uses two separate transport equations. One is for the turbulence kinetic energy, $\mathrm{k}$, and the other is for the rate of dissipation, e. The RNG k-e model is derived using renormalization group theory and is a modified version of the standard two equation k-e model. The difference in the two models is in the constants and the additional terms that are added to the RNG formulas. 


\section{6b Reynolds Stress Model (RSM)}

The most robust 2-D turbulence model available in Fluent 6.1 is the RSM. The

individual Reynolds stresses, $\left(\overline{u_{i}^{\prime} u_{j}^{\prime}}\right)$, are calculated and used to close the Reynolds-

averaged momentum equation. The shorthand version of the combined Reynolds stress transport equations is defined through the following relationship,

$$
\frac{\partial}{\partial t}\left(\rho \overline{u_{i}^{\prime} u_{j}^{\prime}}\right)+C_{i j}=-D_{T, i j}+D_{L, i j}-P_{i j}-G_{i j}+\phi_{i j}-\varepsilon_{i j}-F_{i j}+S_{u s e r} .
$$

The variables are defined as:

$$
\begin{aligned}
& C_{i j} \equiv \text { Convection, } \\
& D_{T, i j} \equiv \text { Turbulent Diffusion, } \\
& D_{L, i j} \equiv \text { Molecular Diffusion, } \\
& P_{i j} \equiv \text { Stress Production, } \\
& G_{i j} \equiv \text { Buoyancy Production, } \\
& \phi_{i j} \equiv \text { Pressure Strain, } \\
& \varepsilon_{i j} \equiv \text { Dissipation, } \\
& F_{i j} \equiv \text { Production by System Rotation, and } \\
& S_{u s e r} \equiv \text { User-Defined Source Term; }
\end{aligned}
$$

where $C_{i j}, D_{L, i j}, P_{i j}$, and $F_{i j}$ are all exact terms. To close the Reynolds stress transport equations, the $D_{T, i j}, G_{i j}, \phi_{i j}$, and $\varepsilon_{i j}$ terms must all be modeled in the software. These inexact terms along with the local time derivative make this a 5 equation turbulence model. This turbulence model is accurate but it uses a lot of computational resources. 


\section{Chapter 3.0: Experiment Setup}

This section describes both the experimental setups and their corresponding numerical setups. The setup of the numerical experiments required two separate software packages. Gambit 2.1 was used to generate the computational grid and Fluent 6.1 was used to solve the flow field. These two software packages make up a tool that can be used to solve most scenarios in aerodynamics.

\subsection{Grid Generation}

A number of grids were created for each experiment. Five grids were created for the NASA experiment and nine were created for the WVU experiment. The grid creation process can be thought of as an art form because there are only general guidelines for creating grids. Many times the first grid needs to be adapted for the flow solver to be able to come up with a solution, and just because the flow solver comes up with a solution does not mean that it is correct. For the modeling of these two experiments it was important to pay close attention to the areas around the airfoil.

\section{1a NASA Experiment}

To simulate the experiment that was done by Felker et al. [17], a two dimensional grid was generated. Though a very important part of the grid generation is simply to create accurate geometry, a complete three dimensional grid was not necessary for this comparison [5]. This was mainly because of the intended use of the solutions. This grid and subsequent solutions were simply a comparison of the computational solution and the NASA experiment to validate that the computational model could provide reasonable results. The grid therefore included a cross section of the wind tunnel with the wing included. 
The NASA experiment was conducted inside a 40- by 80-ft. wind tunnel at Ames Research Center. The model in the wind tunnel included a 0.658 scale model of the V-22 rotor and wing. There was also an image plane setup to simulate the side of the V-22 where the wing meets the fuselage. The wing, rotor, and image plane were all positioned to match the V-22 in hover mode with the wing flap deflected at various angles.

Figure 3.1 shows where the computational grid was placed with respect to the NASA experiment and Figure 3.2 shows an overall view of the computational domain. The width of the grid was $80 \mathrm{ft}$ and the height of the grid was $115 \mathrm{ft}$. In Figure 3.2, each of the lines represent boundaries as they were created using Gambit 2.1. The blue horizontal line on the top of the grid is a velocity inlet and the red line on the bottom is a pressure outlet. The rest of the lines were created as no-slip walls. The velocity inlet is $5.4 \mathrm{ft}$ from the wing in accordance with the distance between the rotor and wing in the experiment. Enough room was also allowed downstream of the wing for any turbulence and vortices to be resolved.

The wing was equipped with five rows of static pressure taps. Each row consisted of 45 taps placed around the airfoil on both the upper and lower surfaces. The data taken with the static pressure taps was the main data used for comparison with the computational model.

The main goal of the computational grid was to model the phenomenon experienced by the static pressure taps for comparison and verification that the turbulence models could be trusted. The grid was created to incorporate the wing with pressure taps. This was not difficult as Fluent 6.1 can compute the pressures on any surface. 


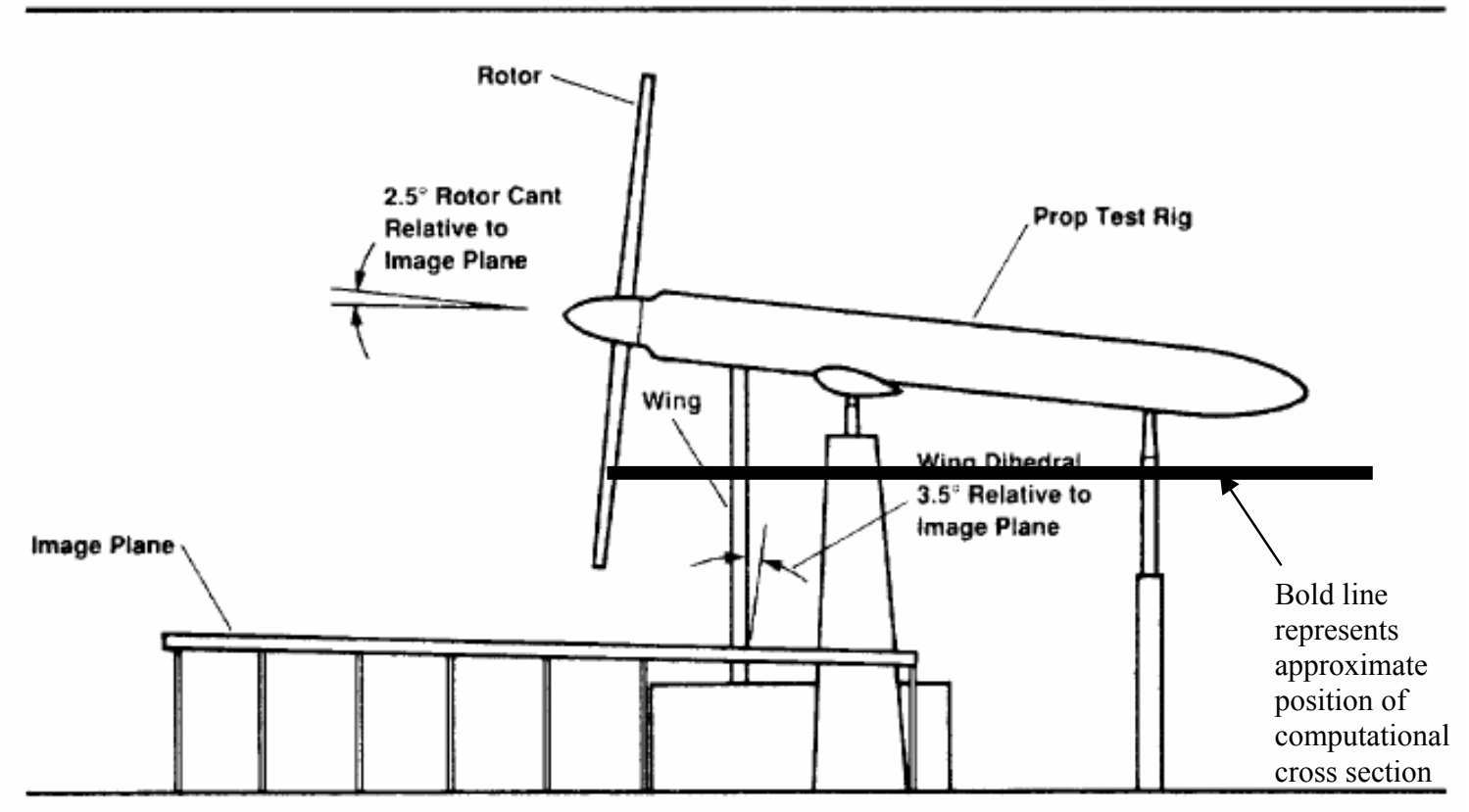

Figure 3.1: Placement of Computational Grid within Felker Experimental Setup

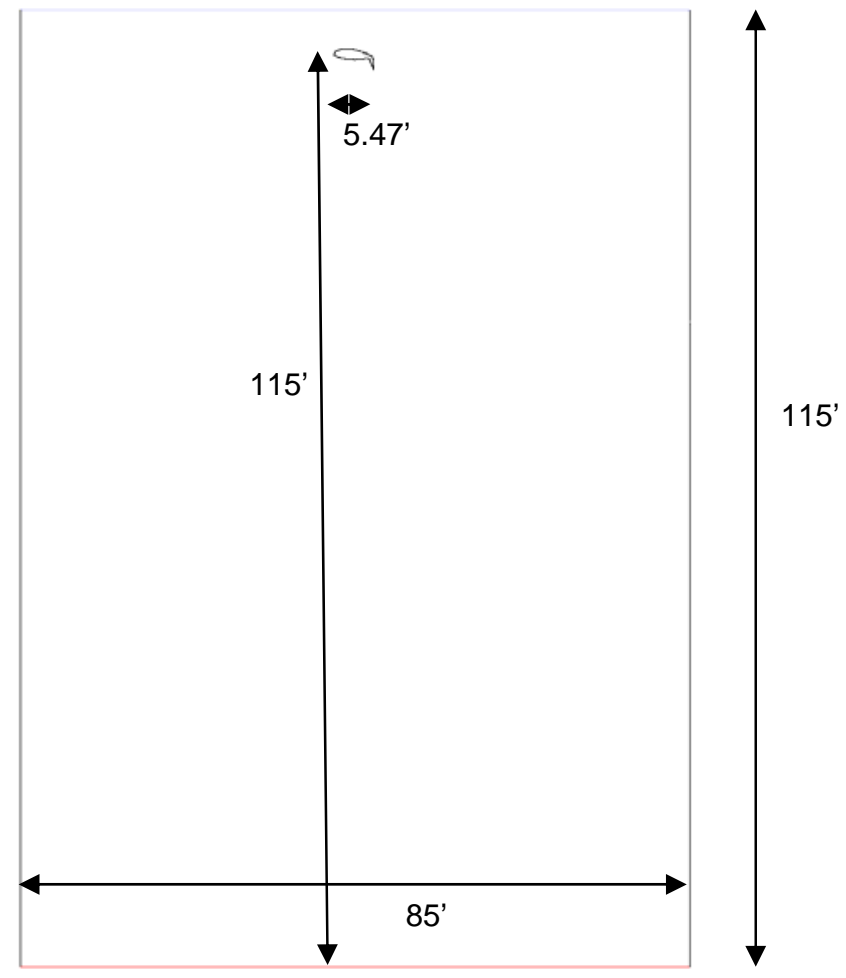

Figure 3.2: Felker Experiment: Overall View of Boundaries for Computational Grid 
The NASA experiment included runs with the flap at various positions, but only one grid was created for the flap deflecting at 67 degrees. This was because the only data available for the other experiment in comparison [18] was for the flap at 67 degrees. It is difficult to notice in Figure 3.2, but just like in the NASA experiment, the leading edge of the wing was rotated five degrees toward the rotor. Using the geometry that was provided from the NASA experiment, a cross section of the V-22's wing with flap deflected 67 degrees was generated to the exact dimensions used in the NASA experiment with one exception; to help the solutions converge, the gap between the main wing and the flap was closed off on both the top and bottom. This differs from the actual experiment which only had the top of the wing closed off by a flap follower/flap seal. The area between the flap and main wing had some sharp corners that reeked havoc on the grid. Specifically, the cells had high skewness between the wing and flap which caused divergence. Figure 3.3 shows the difference between the experimental and computational wing models. Figure 3.3 is not to scale.
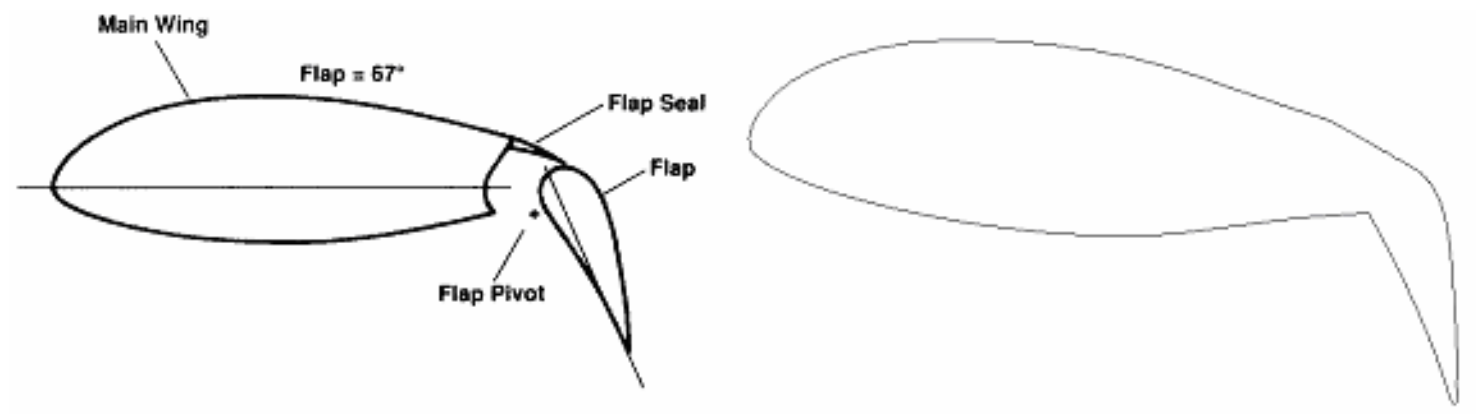

Figure 3.3: Left: Felker Experiment: Experimental Wing Configuration, Right: Computational Wing Configuration

While the grid geometry is important for creating a model that accurately matches the experiment, it is also very important that the grid can resolve all of the flow physics. To make sure the solution was as realistic as possible a high number of grid points were 
used. This specific grid included $1,834,758$ cells. This high number of grid points was used to make sure grid independence was achieved.

Along with the number of grid points, the placement of grid points is very important. Wherever high velocity gradients and shear are expected, there should necessarily be more grid points to resolve the flow in these regions. In the case of this grid, there needed to be more resolution around the leading and trailing edge of the airfoil and immediately downstream of the airfoil. Upstream of the airfoil the velocity inlet provided nearly uniform flow, so not as many grid points were needed [5]. The grid distribution around the airfoil is clearly depicted in Figure 3.4. Regions of near blackness indicate very small and tightly packed computational cells.

For the airfoil, 1,024 2-D wall faces were created. On the top of the airfoil, there are substantially less faces. In an effort to keep the cell skewness to a minimum, a double sided successive ratio was used to fade the compactness of the cells from loose on the very top of the airfoil to tight on the sides. So, the majority of the wall faces are located on the underside and leading and trailing edges of the airfoil.

For the turbulence model that was used (RNG k-e), Fluent documentation recommends having enough grid points around the wall to achieve a $\mathrm{y}^{+}$value between one and five [19]. Along the top surface of the airfoil, the $\mathrm{y}^{+}$value was approximately 1,000. Below the wing, where the flow becomes much more turbulent, the cells were packed much more closely resulting in a $\mathrm{y}^{+}$value of approximately eight. This value is not between one and five; however, Fluent's enhanced wall treatment scheme can do a good job of compensating for a higher $\mathrm{y}^{+}$value [11]. 


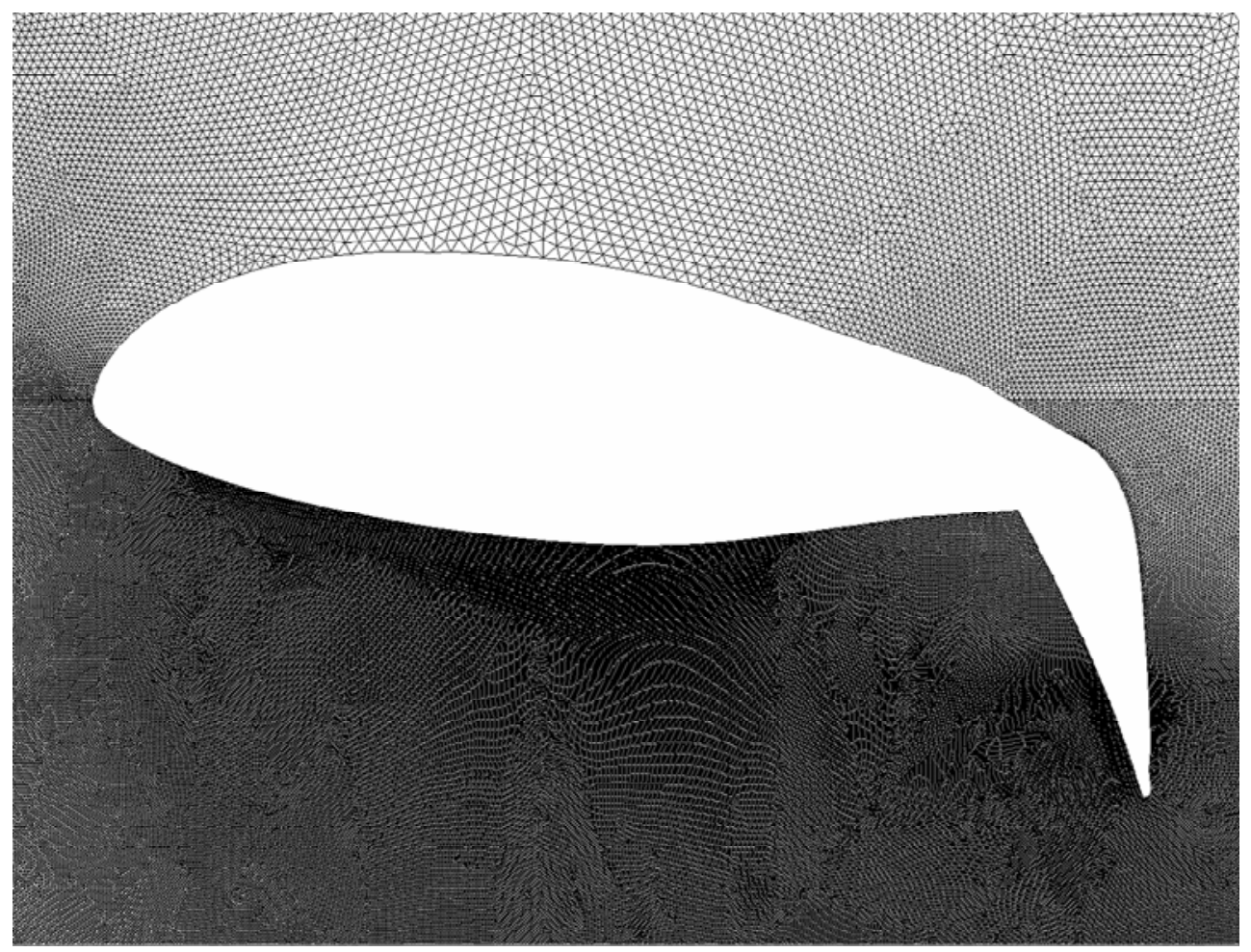

Figure 3.4: Felker Experiment: Computational Grid close to the Airfoil

Figure 3.4 also shows that an unstructured triangular mesh was used. This was mainly done to save time in the grid creation process. Fluent's user guide provided three criterions for meshing a grid, the first being setup time. Since the area around the flap has some sharp corners combined with some sweeping curves, coming up with a structured grid in that area would take some extra time. An unstructured grid, on the other hand, can quickly fill in all of the areas around the airfoil. The next consideration was computational expense. For simple geometry it is possible to create a structured grid that will have less grid points. For more complex geometry, however, it is easier to put grid points only in the regions where they are needed most using an unstructured grid, thus allowing less grid points to be used overall. In this particular case it was unclear as to which would have been better from a computational expense perspective, but the next consideration was convincing for the use of an unstructured grid. Numerical diffusion 
can lead to incorrect solutions, and a small amount of numerical diffusion is unavoidable. In simple flows, it is possible to align a structured grid with the flow; in complex flows, this is impossible to do because of the nature of turbulent flow. So long as the grid was properly refined in the right areas, it was reasonable to use an unstructured grid. Also, it is convenient that Fluent is written in an unstructured framework which further lends to the use of an unstructured grid [11].

\section{1b WVU Experiment}

The experiment conducted in West Virginia University's Closed Loop Wind Tunnel was setup to test a 0.019 scale V-22 wing equipped with blowing slots in hover mode. A scale model of a Bell A821201 airfoil with blowing slots that ran along the span on the leading and trailing edges was placed in the wind tunnel. The span of the wing was 18 inches and its chord length was 19 inches. To simulate downwash over the wing, the wind tunnel was set to a free stream velocity of 59 fps and the wing was oriented accordingly. The flap was deflected 67 degrees in accordance with the V-22's standard hover mode configuration.

A baseline test was done with the blowing slots turned off. Tests were later run with blowing pressures of $5,10,15,20$, and 25 psig in both blowing slots. For each test, the forces were measured on the wing and a wake rake was used to measure the pressures 24 inches downstream of the wing.

The grid creation process was very similar from what was done for the NASA experiment. Gambit 2.1 was used to create the computational grid and boundaries. A two dimensional grid was created based on a cross section of the WVU wind tunnel. The overall dimensions of the grid can be seen in Figure 3.5. The general setup used was a 
two-dimensional cross section of the wind tunnel test section with a 0.019 scale model of a Bell A821201 airfoil equipped with 0.0625 inch blowing slots. The leading and trailing edge blowing slots are located at 1.61 and 70.55 percent of the chord length, respectively. To clarify Figure 3.5, the actual chord length in the experimental and computational setup was 19 inches; the number that is displayed in Figure 3.5 of 16.76 inches is the length from the leading edge of the airfoil to the end of the 67 degree rotated flap. The width of the computational test section was 48 inches and the length was set as 84 inches. This length was chosen so that the wake profile could be adequately captured.

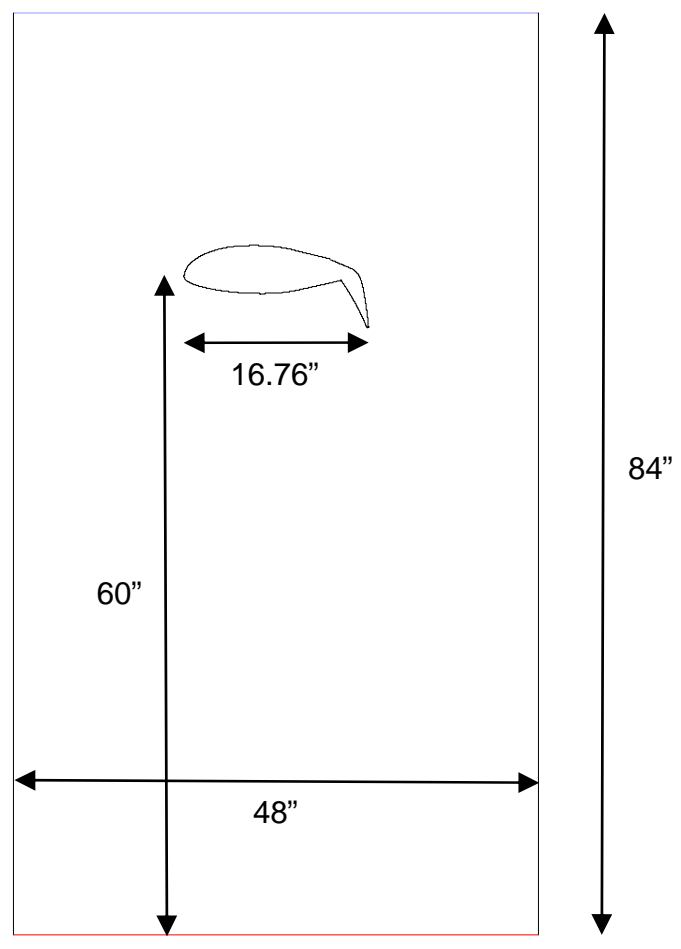

Figure 3.5: WVU Experiment: Overall View of Boundaries for Computational Grid

Once again, Gambit 2.1 allowed the creation of various types of boundaries. At the top of the grid a velocity inlet that produced a uniform downward airflow was created. The bottom of the grid was specified as a pressure outlet. Each of the blowing slots was created as velocity inlets. The rest of the boundaries were set as no-slip walls. 
The mesh was created using unstructured triangular cells. Extra grid points were clustered around the blowing slots and immediately downstream of the wing, where large gradients and flow separation were expected. 2,131 grid points were created around the airfoil, which resulted in an average $\mathrm{y}^{+}$value of approximately 12 for cells next to the wall and very close to the blowing slot. The entire grid was comprised of $2,184,528$ triangular cells and 1,093,464 nodes. Figure 3.6 shows the overall grid, and Figure 3.7 shows a close up of the grid on the leading edge.

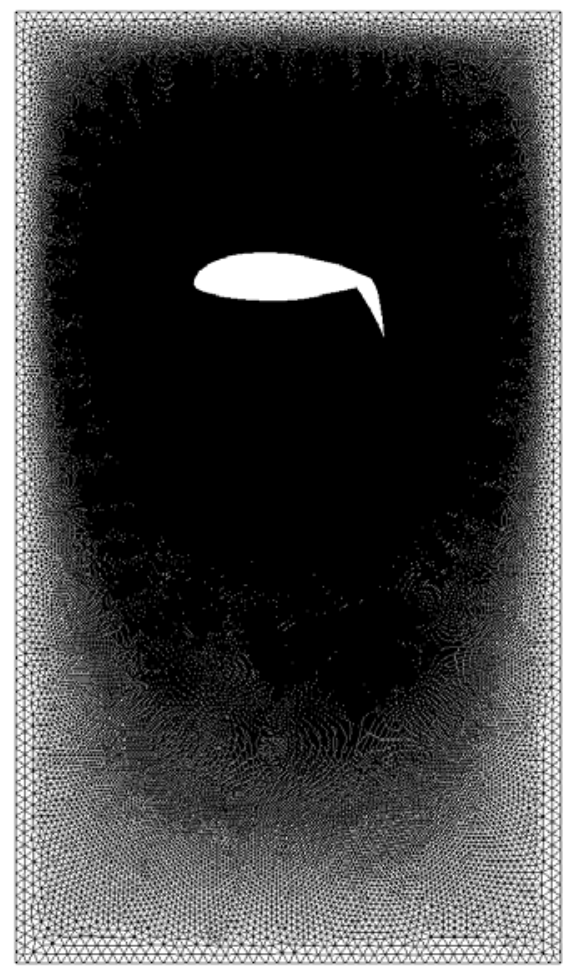

Figure 3.6: WVU Experiment: View of entire Computational Grid 


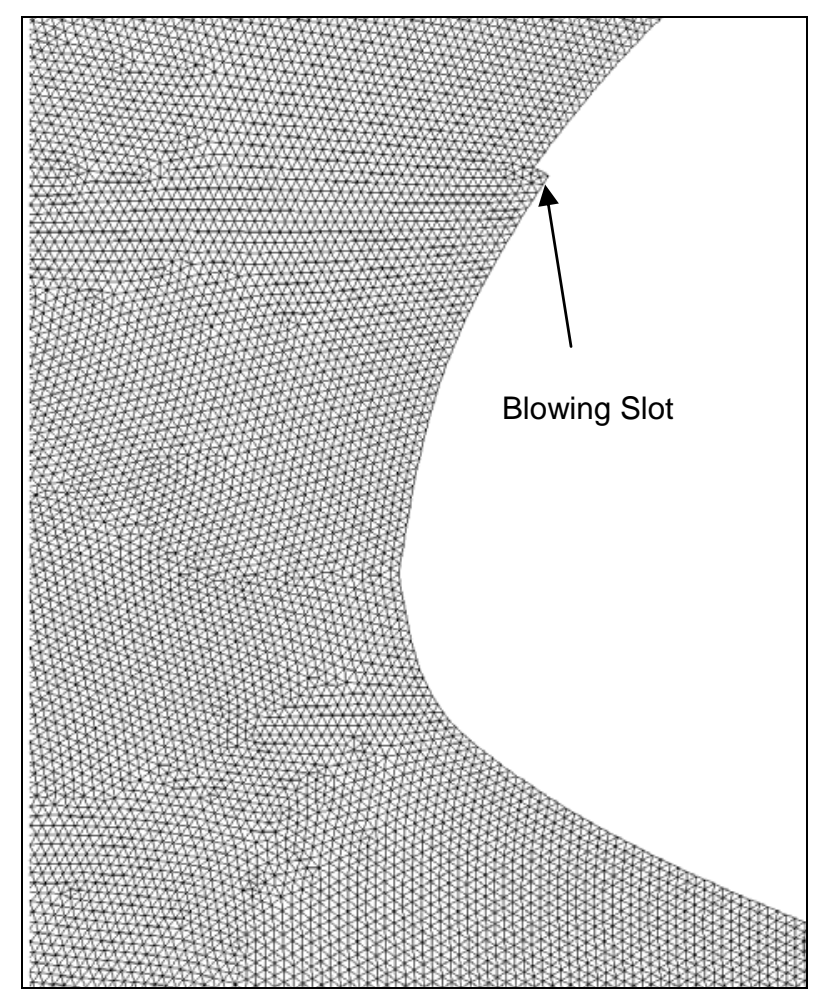

Figure 3.7: WVU Experiment: Computational Grid close to Blowing Slot

\subsection{Initial Conditions}

\section{2a NASA Experiment}

In the NASA experiment, the downwash over the wing was created using a 0.658 scale model of a V-22 rotor. Run six from the NASA experiment was chosen for the comparison. The air density and pressure were $0.002355 \mathrm{slug} / \mathrm{ft}^{3}$ and $2122 \mathrm{lb} / \mathrm{ft}^{2}$ respectively. The temperature of the air and its surroundings were set to $522.47^{\circ} \mathrm{R}$. The flap was set to 67 degrees and the rotor produced $11,078 \mathrm{lb}$ of thrust.

Instead of an actual moving rotor, a velocity inlet was used to approximate the downwash onto the wing in the computational model. A constant velocity of $100 \mathrm{fps}$ was set across the entire inlet. This is an approximation to the actual experiment. It is difficult to determine the actual downwash velocity that a rotor creates. A first approximation was determined using actuator disk theory. This theory states that the 
rotor is a uniformly thin disk which produces no resistance to air flowing through it. Also, thrust loading and velocity are uniform over the disk, viscous effects are not included, and the flow is assumed incompressible. The result of the above assumptions is

$$
T=\dot{m}\left(V_{e}-V_{o}\right)
$$

which can be simplified to:

$$
V_{\text {ind }}=\sqrt{\frac{T}{2 \rho A}} .
$$

Equation 3.2 can be used to find an approximate downwash velocity of 138.44 fps from the experimental thrust, density, and rotor area. Of course, the rotor is not ideal, so to try to account for viscous drag, non-uniform inflow, swirl in the wake, and tip losses a downwash of 100 fps was chosen. This is on par with approximations that estimate a Figure of Merit for a good propeller to be around 0.8 [19]. The Figure of Merit is defined as the ratio of ideal power to the actual power then,

$$
F M=\frac{P_{\text {ideal }}}{P_{\text {act }}}
$$

The airflow was allowed to exit out of the bottom of the grid through a pressureoutlet that was set to zero gauge pressure. This is similar to the NASA experiment which had exhaust vanes for the wind tunnel fully opened to try and simulate free-air test conditions. The operating pressure was set to $2,122 \mathrm{lb} / \mathrm{ft}^{2}$ to match the test conditions for the experiment and the air density was initially set to $0.002355 \mathrm{slug} / \mathrm{ft}^{3}$ throughout the entire flow domain. 


\section{2b WVU Experiment}

The initial conditions for the WVU experiment proved difficult to set because the method used to vary the mass flow coming out of the blowing slots was to vary the plenum pressure. A first attempt was made to create blowing slots by simply creating pressure outlets where the blowing slots would be. However, without the plenum built into the grid, the pressure outlets did not provide realistic flow. In fact, the velocities coming out of the pressure outlet blowing slots exceeded sonic conditions on average by twice the speed of sound. This was clearly not realistic since air flowing out of a nozzle can only reach a maximum velocity of Mach one. Furthermore, sonic speeds would be almost impossible to create in a full size application because of the power requirements.

In order to match the experiment, velocity inlets were used to simulate the blowing slots, yet, slot velocities from the experiment were not readily available. Therefore, the blowing slot momentum coefficient was used to match experiment to simulation. The blowing slot momentum coefficient is defined as the nondimensionalized mass flow rate times the velocity out of the slot. This is shown in the following relationship where,

$$
C_{\mu}=\frac{\dot{m} V_{j}}{\frac{1}{2} \rho_{\infty} U_{\infty}^{2} c}=\frac{\rho_{j} V_{j}^{2} h b}{\frac{1}{2} \rho_{\infty} V_{\infty}^{2} c b} .
$$

Using the known geometries and data from the experiment, the plenum pressures were converted to the blowing slot momentum coefficient. Through the use of Equation 3.4, it was then possible to pick reasonable velocities for the blowing slot velocity outlets so they would match the experiment. Table 3.1 and Table 3.2 show the corresponding blowing slot momentum coefficients for each experimental pressure and each simulation 
velocity, respectively. Five separate cases were created for the slot velocities of 0,10 , 60,130 , and 200 fps.

Table 3.1: Experimental Slot Pressure and Corresponding Momentum Coefficient

\begin{tabular}{|c|c|}
\hline Slot P [psi] & $\mathbf{C}_{\boldsymbol{\mu}}$ \\
\hline 0 & 0 \\
\hline 5 & 0.0116 \\
\hline 10 & 0.0232 \\
\hline 15 & 0.0348 \\
\hline 20 & 0.0464 \\
\hline 25 & 0.0580 \\
\hline
\end{tabular}

Table 3.2: Computational Slot Velocity and Corresponding Momentum Coefficient

\begin{tabular}{|c|c|}
\hline Slot V [ft/s] & $\mathbf{C}_{\boldsymbol{\mu}}$ \\
\hline 0 & 0 \\
\hline 10 & 0.0002 \\
\hline 60 & 0.0068 \\
\hline 130 & 0.0319 \\
\hline 200 & 0.0756 \\
\hline
\end{tabular}

The velocity inlet at the top of the grid was set to $59 \mathrm{fps}$ to match the velocity in the WVU wind tunnel. The pressure outlet was set to zero gauge pressure. The operating pressure was set to $2,116.228 \mathrm{lb} / \mathrm{ft}^{2}$ and the air density was set to $0.002375 \mathrm{slug} / \mathrm{ft}^{3}$. Finally, the entire flow field was initialized at the velocity inlet condition of $59 \mathrm{fps}$ downward. 


\section{Chapter 4.0: Solution Procedure}

The CFD software that was used was the commercially available Fluent 6.1. The first step of the solution procedure was to come up with a laminar solution. To do this, the above initial conditions were used and the following settings were used in the software:

- Fluent's laminar model was used with the 2-D, double precision, segregated solver;

- The first order upwind discretization technique was used to solve the momentum equation;

- Fluent's PRESTO! scheme was used for the pressure;

- Both the density and viscosity were set as constant properties; and,

- The energy equation was turned off.

These settings allowed for a fairly quick solution to converge. Each setting was chosen to simplify the flow field as much as possible so that a quick solution could be reached. Double precision was used on all solutions to improve accuracy. The segregated solver was used because it had provided accurate results in previous work [5].

The laminar solution provided a good initial flow field for use in the turbulence model solution. The next step involved using the RNG-ke turbulence model. This turbulence model was chosen for a variety of reasons.

The main consideration when selecting any computational model is to get an accurate solution while keeping computing expense to a minimum. So, if it is possible to use a one or two equation model that provides only marginally different results from the full five equation RSM model, then it would be advantageous to do so. Fluent 
documentation, describes the k-e model as being robust, economic, and reasonably accurate [19]. The RNG k-e model adds extra refinement and makes it a good candidate for the current study, including enhanced accuracy for rapidly strained flows, swirling turbulence, and lower Reynolds numbers.

Along with the general guidelines given by the Fluent documentation [19], full studies have already been conducted to test turbulence models for use in active circulation control. A study done by J. F. Slomski, et al. [11] showed that for blowing coefficients lower than 0.1 , the k-e turbulence model provided accurate results. Since the highest blowing coefficient considered was 0.0756 , the RNG k-e model was preliminarily picked to simulate the NASA experiment.

To further validate the use of the RNG k-e model, a quick study was done. This study included solving the flow field with both the RNG k-e model and the Reynolds Stress Model using the laminar solution as a base. The RSM is considered to be the most accurate and most expensive of the 2-D turbulence models available in Fluent 6.1. So, if good agreement could be found between the two simulations then the RNG k-e model would be an acceptable model. Figure 4.1 shows the comparison between the two models. The results were similar, so the RNG k-e model was chosen to continue the experiments.

Using the laminar solution to initialize the flowfield, the following settings were used to come up with the RNG k-e solution:

- Fluent's RNG k-e model was used with the 2-D, steady, double precision, enhanced wall treatment, segregated solver; 
- Second order upwinding discretization was used to solve the momentum, turbulence kinetic energy, and turbulence dissipation rate equations;

- The pressure was solved with second order accuracy;

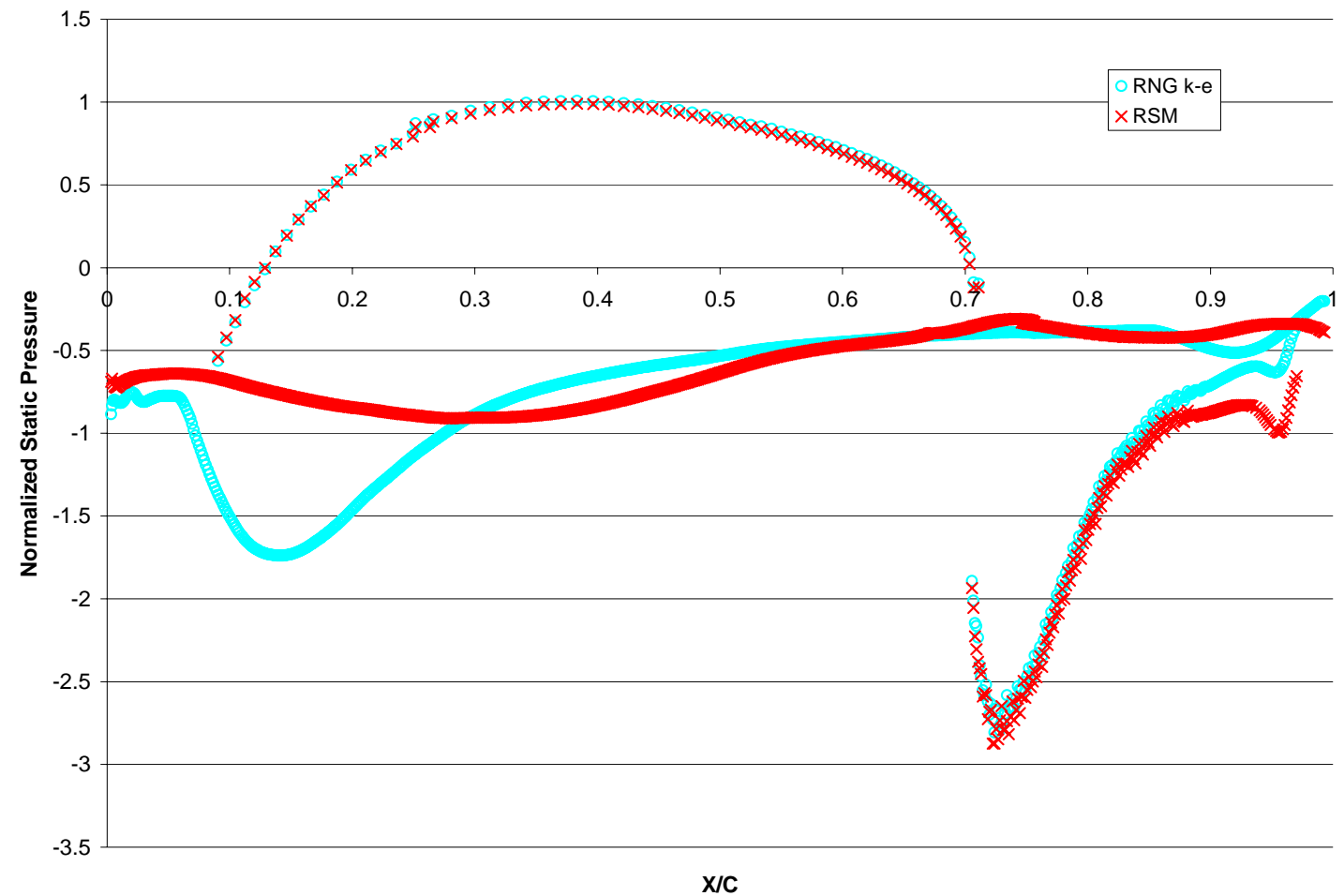

Figure 4.1: Comparison of RNG k-e and RSM Turbulence Models

- Both the density and viscosity were set as constant properties; and,

- The energy equation was turned on.

Enhanced wall treatment was used so that Fluent would use the proper wall functions near the wall. Second order upwinding is necessary for the solution to be considered accurate. Fluent documentation recommends that second order upwinding should be used to avoid numerical diffusion that is inherently produced when using a triangular mesh [19]. The energy equation was mainly used to check for relatively high 
temperature gradients so that the constant viscosity and density assumption could be validated. An unsteady solution was not done because of troubles with convergence. 


\section{Chapter 5.0: Results}

\subsection{NASA Experiment}

The results for the NASA experiment were used as a comparison to determine the validity of the computational model. This tested how well all of the different factors in creating a computational model worked, including; the grid, the turbulence model, and the settings that were used in Fluent 6.1. The easiest results to compare from the NASA experiment were given as normalized static pressures around the airfoil. These results are probably also the best for comparison because the pressures all around the airfoil can be matched. This pressure profile is fairly critical, especially when circulation is being considered, because regions of separation and high velocity gradients can be identified by changes in the pressures on the airfoil. Figure 5.1 shows the computational results and the experimental results for the normalized static pressures around the airfoil. Experimental results are shown for $0.25,0.45,0.65$, and 0.85 rotor radii from the rotor axis of rotation. The results show the most agreement at 0.45 radii. There is some discrepancy near the leading edge.

\subsection{WVU Experiment}

The results for the WVU experiment included more than just direct comparison between the experimental and computational models. To make sure that the results appeared to be realistic with respect to circulation control, data was looked at concerning flow separation, pressures in the wake, circulation near the blowing slots, and overall download on the wing. 


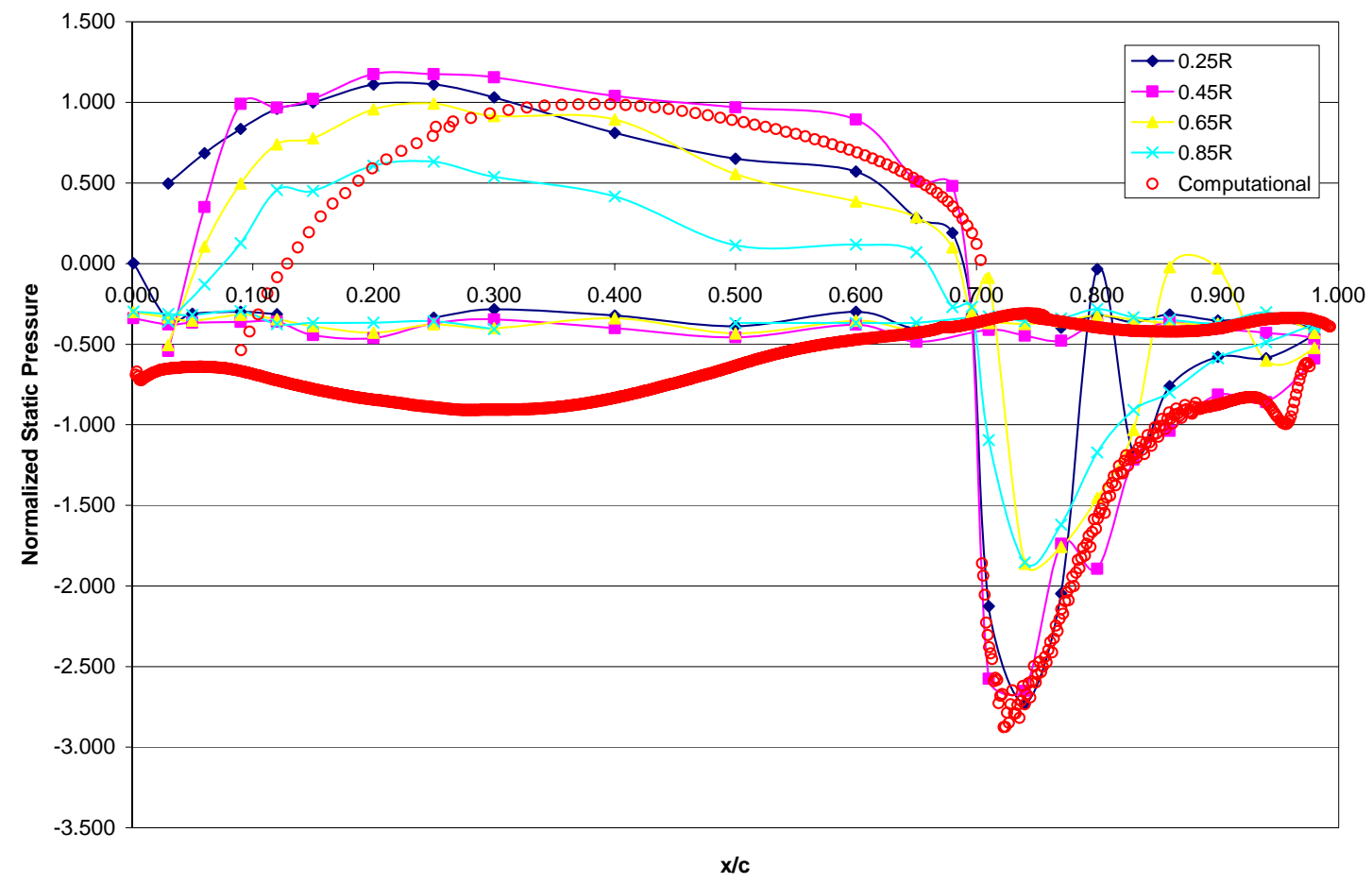

Figure 5.1: Comparison of Computational and Experimental Results for the NASA Experiment

\section{2a Flow Separation}

A key piece of evidence to test how the turbulence model is working with respect to circulation control is to look at where the flow separates downstream of the blowing slots. When the computational model is not working correctly, the results often show dramatically increased circulation. With normal circulation control airfoils this can mean that the airflow actually circulates all the way around the airfoil, sometimes more than once [11]. More realistic results should show an increase in circulation but on a much smaller scale. The results obtained here show that the blowing slots can move the separation point in both directions to increase circulation and reduce it.

After each blowing slot velocity case was solved, 10, 60, 130, and $200 \mathrm{fps}$, the first data that was looked at were velocity vector plots. A baseline test was also performed with the blowing slots set to zero fps. The velocity vector plots could be used 
to approximately identify where flow separation occurred. While flow separation points could not be directly compared to the experimental data, it was still considered useful. If the flow remained attached longer there would most likely be a reduction in download on the airfoil. On the trailing edge, the separation point was always at the end of the flap where there was a sharp corner, whereas on the leading edge, the separation point moved in small increments depending on the blowing slot velocity. These separation point positions were determined by plotting the velocity vectors for each blowing slot velocity and looking at where the velocities abruptly changed directions, indicating separation. The velocity vector plots are shown in Appendix B in Figures B.1 through B.4. A simplified plot showing each separation point along the leading edge is shown in Figure 5.2. Each dot with a corresponding number in Figure 5.2 represents a blowing slot velocity separation point. The size of the cells in the area of the separation is 0.0200 inches while the distance between points one and four is approximately 0.0625 inches.

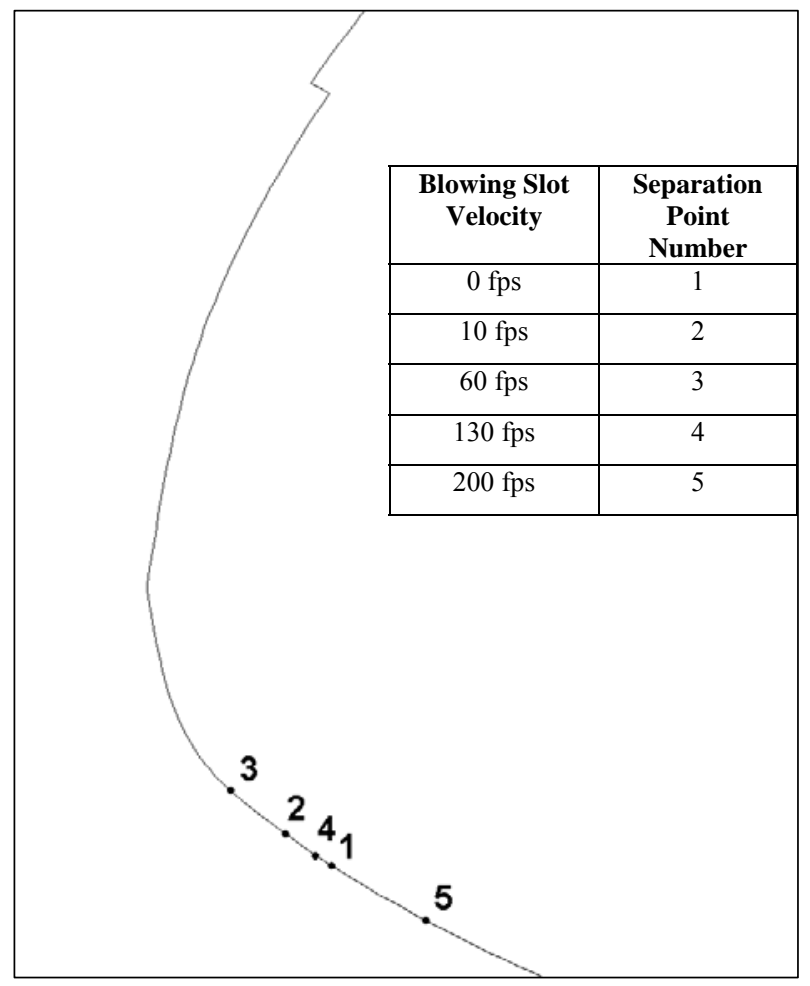

Figure 5.2: Separation Point for Various Blowing Slot Velocities 
When the blowing slot velocity was $10 \mathrm{fps}$, the separation point moved upstream of the baseline separation point. This undesired effect happened because the jet velocity was significantly slower than the surrounding fluid that it was being injected into. Therefore, the momentum of air that exited out of the jet was also significantly lower than the free stream momentum. When the blowing slot velocity was much faster, 200 fps, the separation point moved downstream of the baseline test. The momentum in the jet was much higher than the surrounding fluid so it remained attached longer. This can also be seen in the velocity vector plots in Appendix B, Figures B.1 through B.4, where higher velocities are represented by red and slower velocities are represented by blue or green.

\section{2b Circulation}

While the separation point is a good indicator of how much the download is being reduced, it is also useful to be able to visualize the areas of lower pressure, e.g. where the flow is recirculating, with vector plots and vorticity plots. Immediately behind the separation points, at both the leading and trailing edges, turbulent eddies formed along with larger scale vortices. These regions created lower pressures underneath the wing that increased the download. With the blowing slots in place it was found that these low pressure regions could be reduced in size and the low pressure would rise. This increased pressure was mostly a result of the momentum added to the airflow by the blowing slots. Figures 5.3 through 5.7 show the total pressure contours underneath the wing for each blowing slot velocity. It is important to note that each contour plot has a different pressure scale. The highest blowing case, $200 \mathrm{fps}$, appears to have the largest low pressure region, but the low pressures are less negative. 


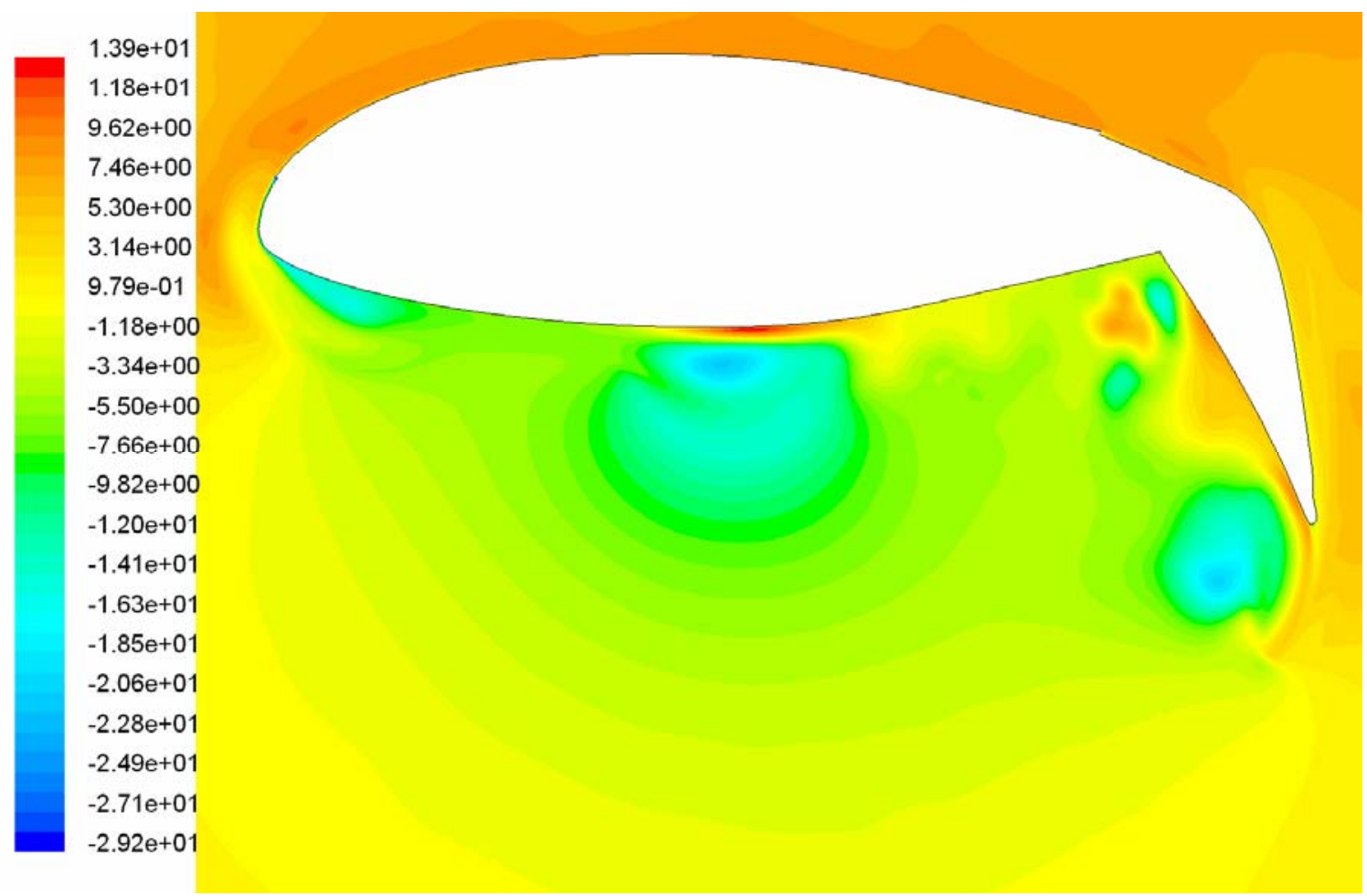

Figure 5.3: Contours of Total Pressure (lb/ft $\left.{ }^{2}\right)$, Blowing Slot Velocity: 0 fps

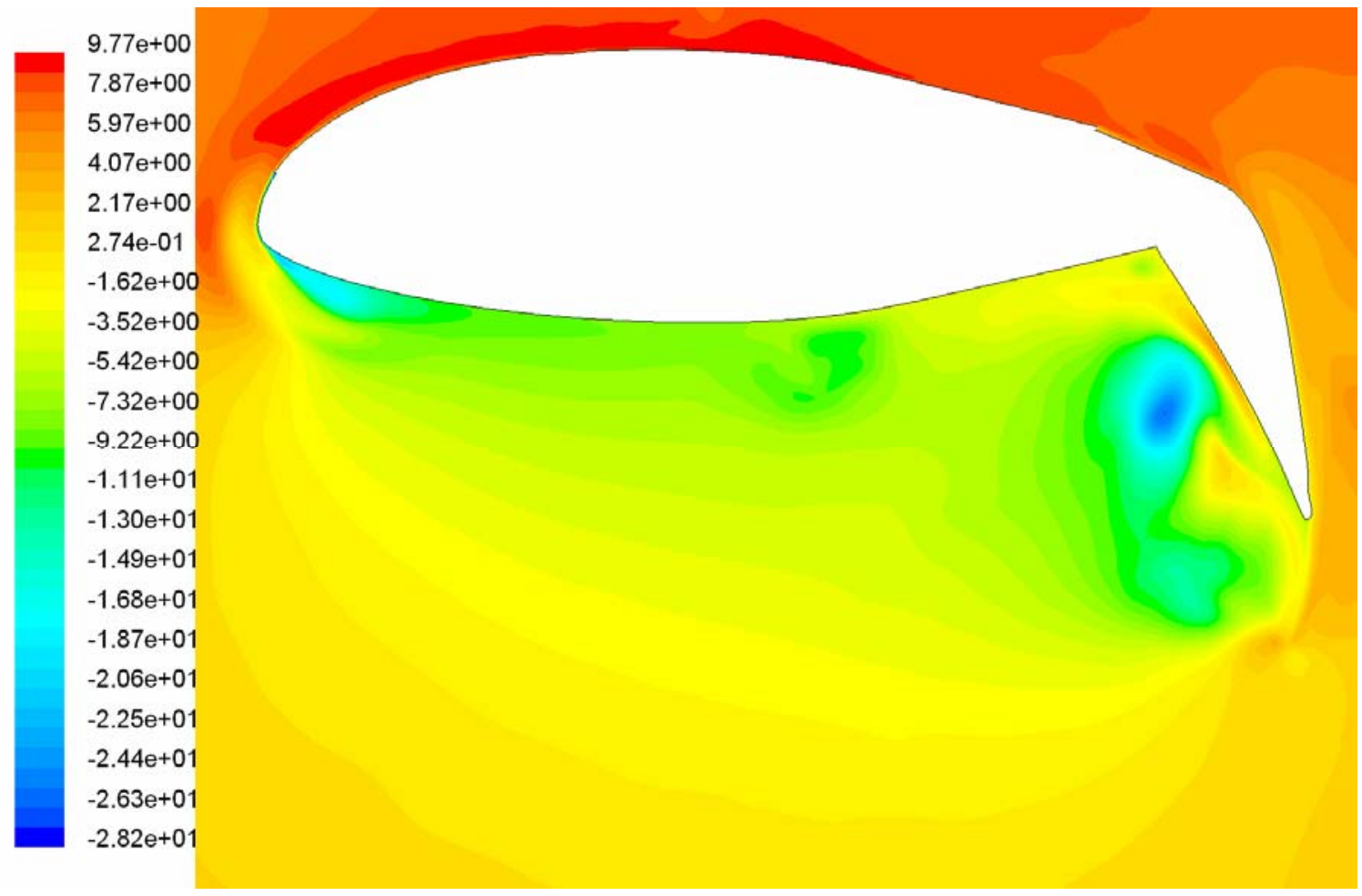

Figure 5.4: Contours of Total Pressure (lb/ft $\left.{ }^{2}\right)$, Blowing Slot Velocity: $10 \mathrm{fps}$ 


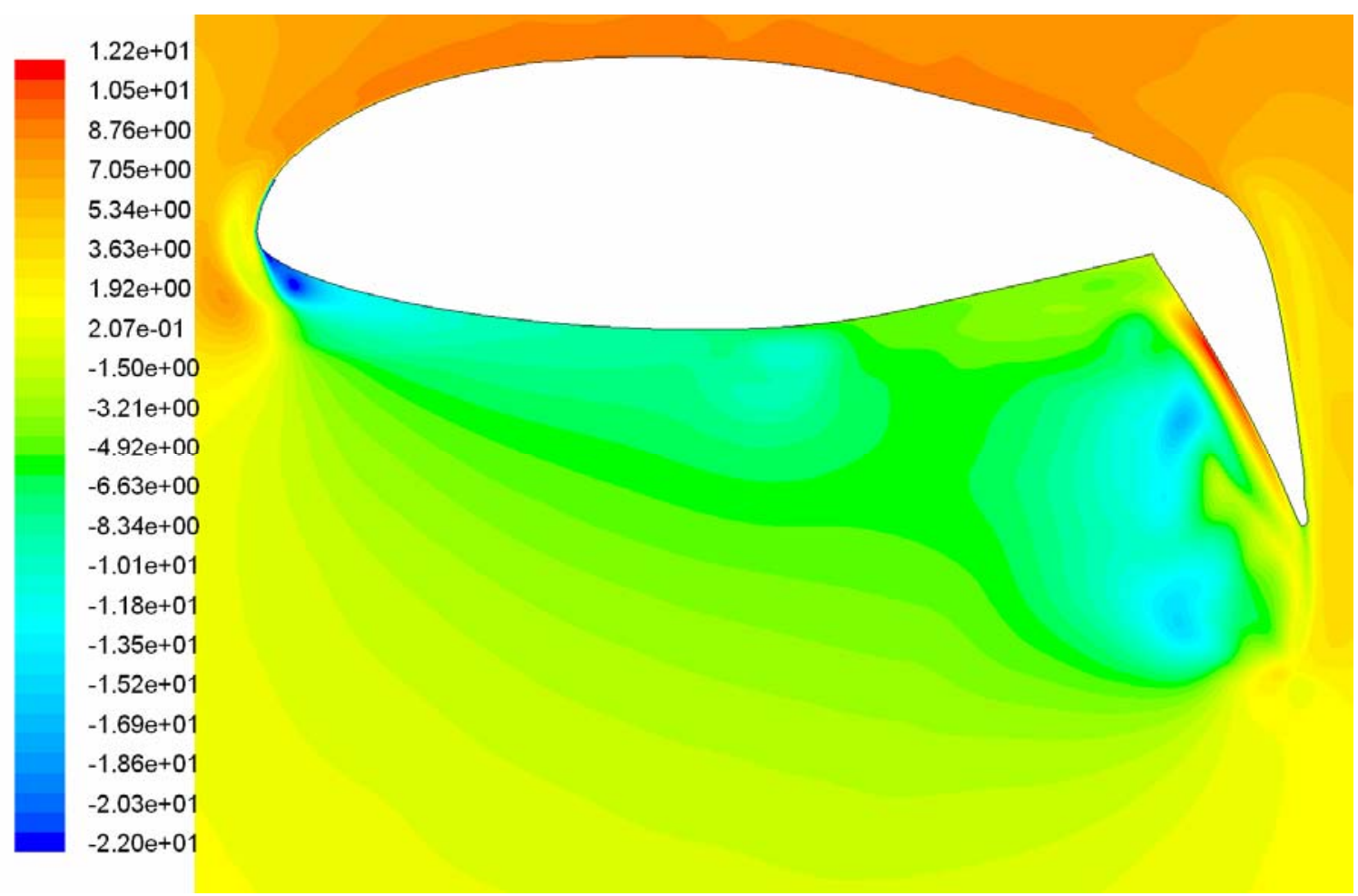

Figure 5.5: Contours of Total Pressure (lb/ft $\left.{ }^{2}\right)$, Blowing Slot Velocity: 60 fps

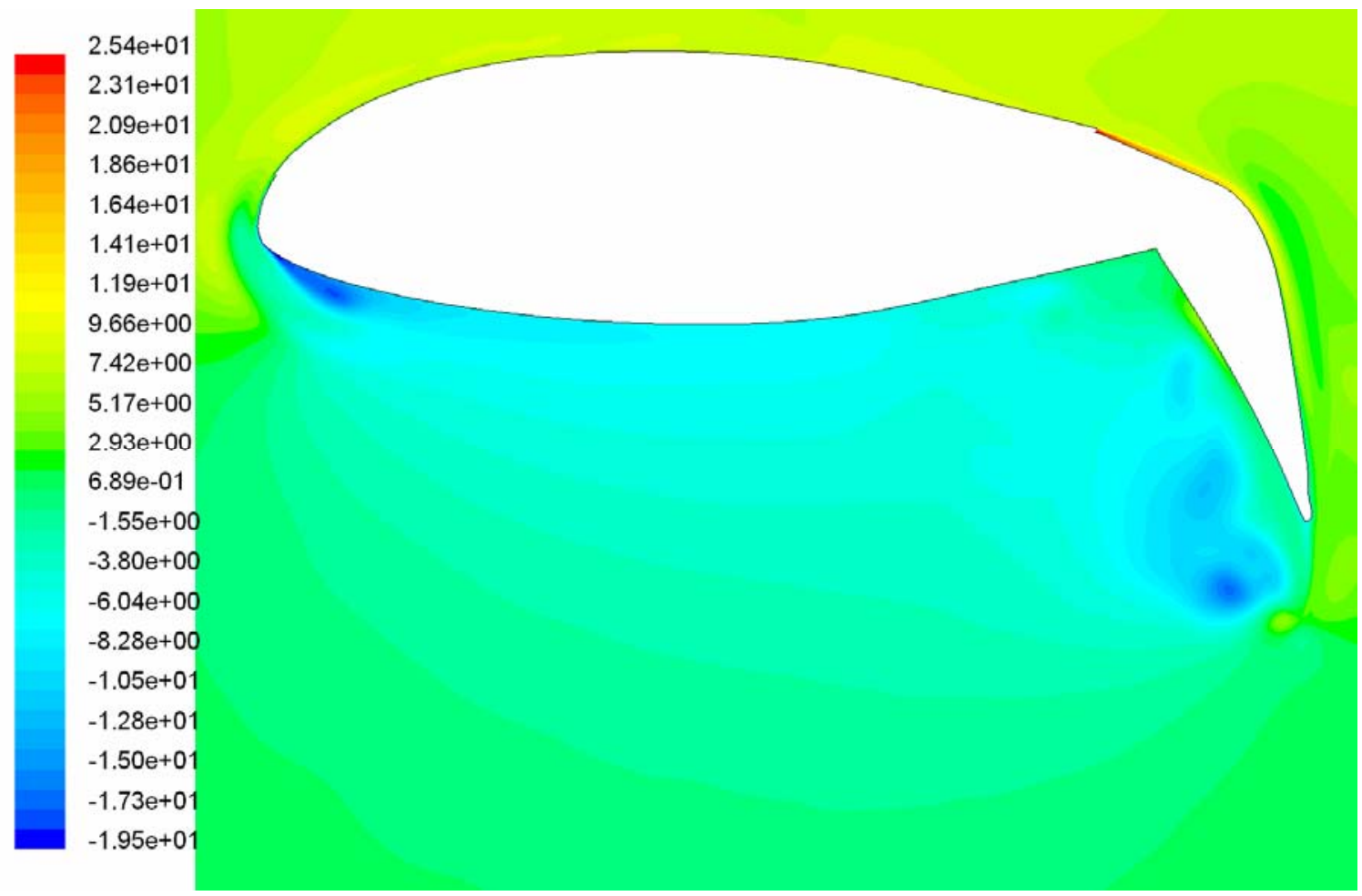

Figure 5.6: Contours of Total Pressure (lb/ft $\left.{ }^{2}\right)$, Blowing Slot Velocity: $130 \mathrm{fps}$ 


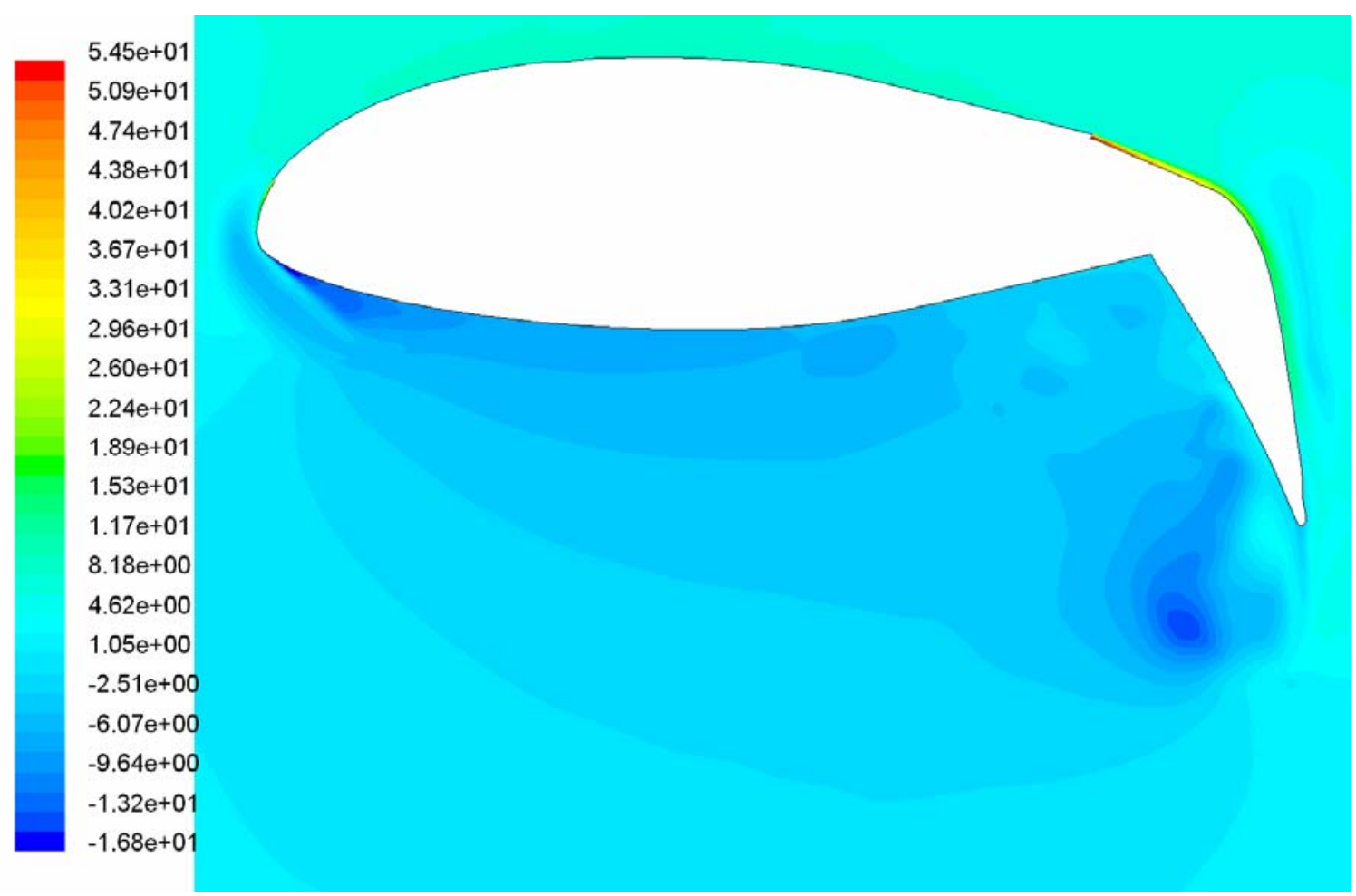

Figure 5.7: Contours of Total Pressure (lb/ft $\left.{ }^{2}\right)$, Blowing Slot Velocity: 200 fps

Flow separation is easily seen by plotting pathlines in the regions behind the blowing slots. Figure 5.8 and Figure 5.9 show particle tracks that are colored by particle identification. These figures are helpful from a circulation control point of view and seem to be similar to other active circulation control studies such as the one done by Swanson, 2005 [7].

Pathlines only tell part of the story for download reduction; they don't really show where turbulence or velocity gradients can be found. Upstream of the wing, the flow appears to be mostly uniform and laminar and immediately downstream of the wing large amounts of turbulence form. This is shown in Figure 5.10, which is a vorticity contour plot around the airfoil domain. The highest values of vorticity are actually in the jets of air coming out of the blowing slots. These high values were cut out so that the turbulence just down stream of the leading edge and flap could be seen. 


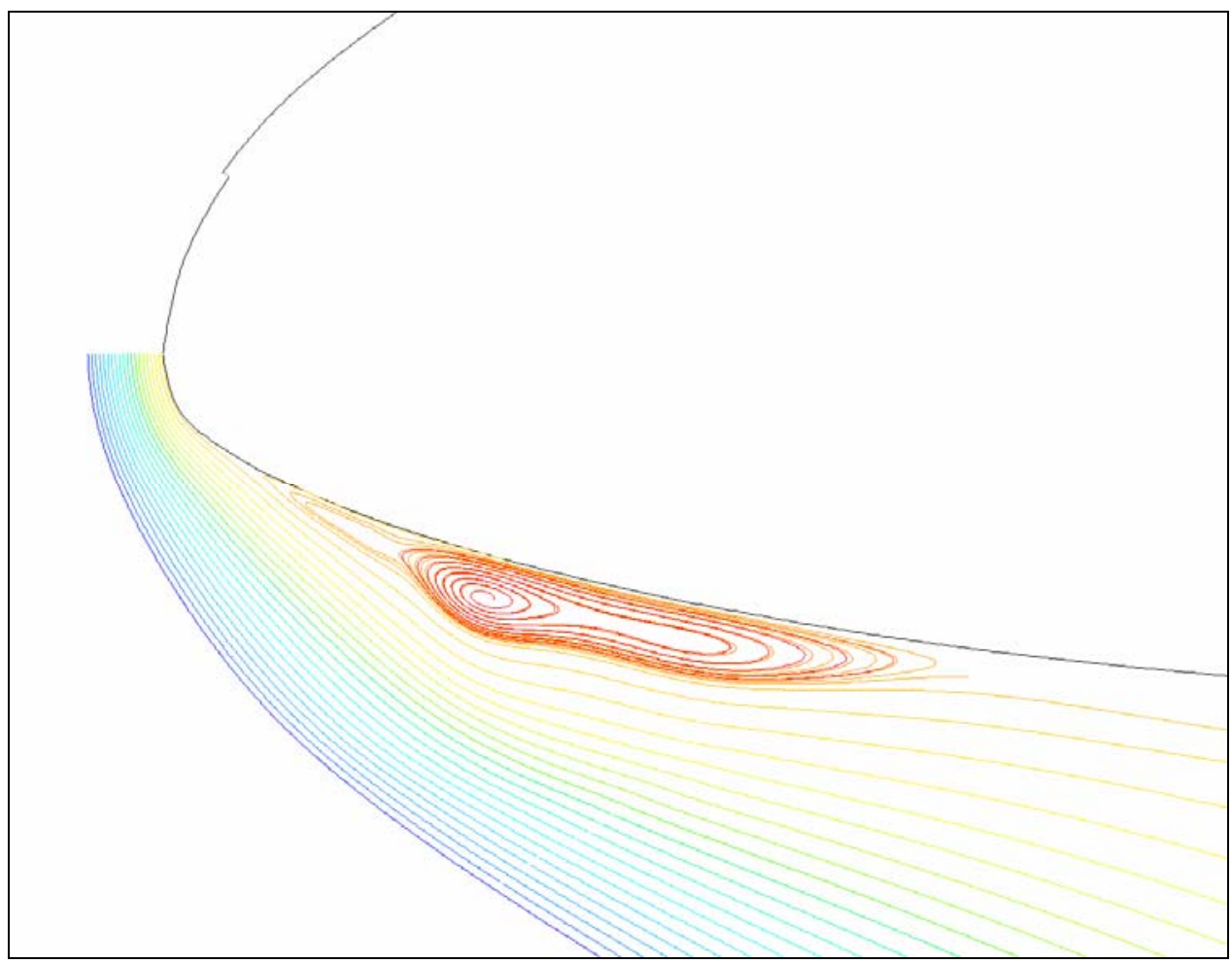

Figure 5.8: Pathlines colored by Particle ID near the Leading Edge

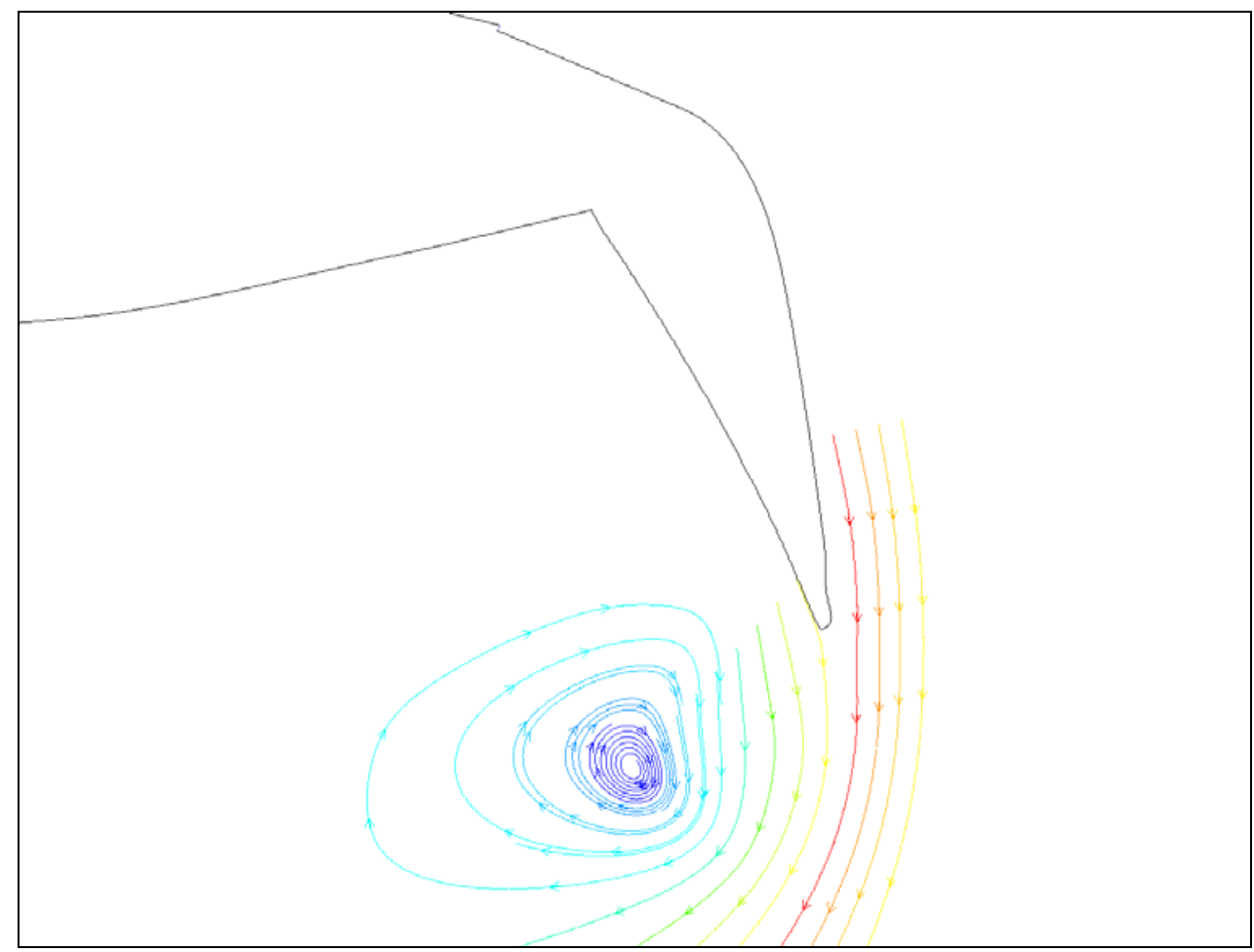

Figure 5.9: Pathlines colored by Particle ID near the Trailing Edge 
Figure 5.11 and Figure 5.12 show the velocity vector plots at the leading and trailing edges, respectively. It is shown in the close up figures that large vortices form just underneath the leading edge and at the end of the flap. Figure 5.10, 5.11, and 5.12 are all for the $200 \mathrm{fps}$ blowing slot case. Velocity vector plots for the rest of the blowing cases are shown in color in Appendix B. The rest of the velocity vector plots all show similar circulation around the airfoil.

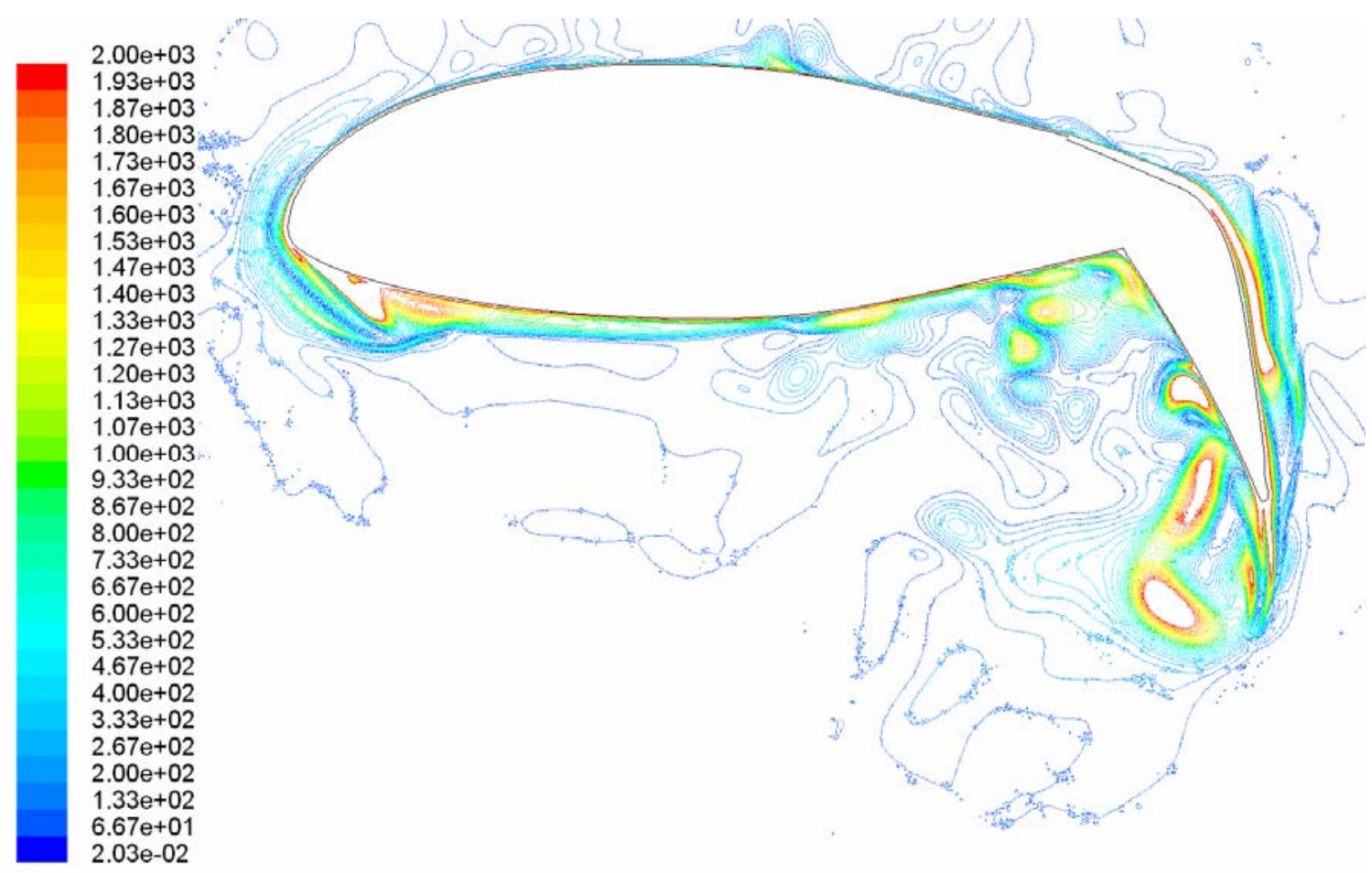

Figure 5.10: Contours of Vorticity Magnitude around the Airfoil in 1/s 


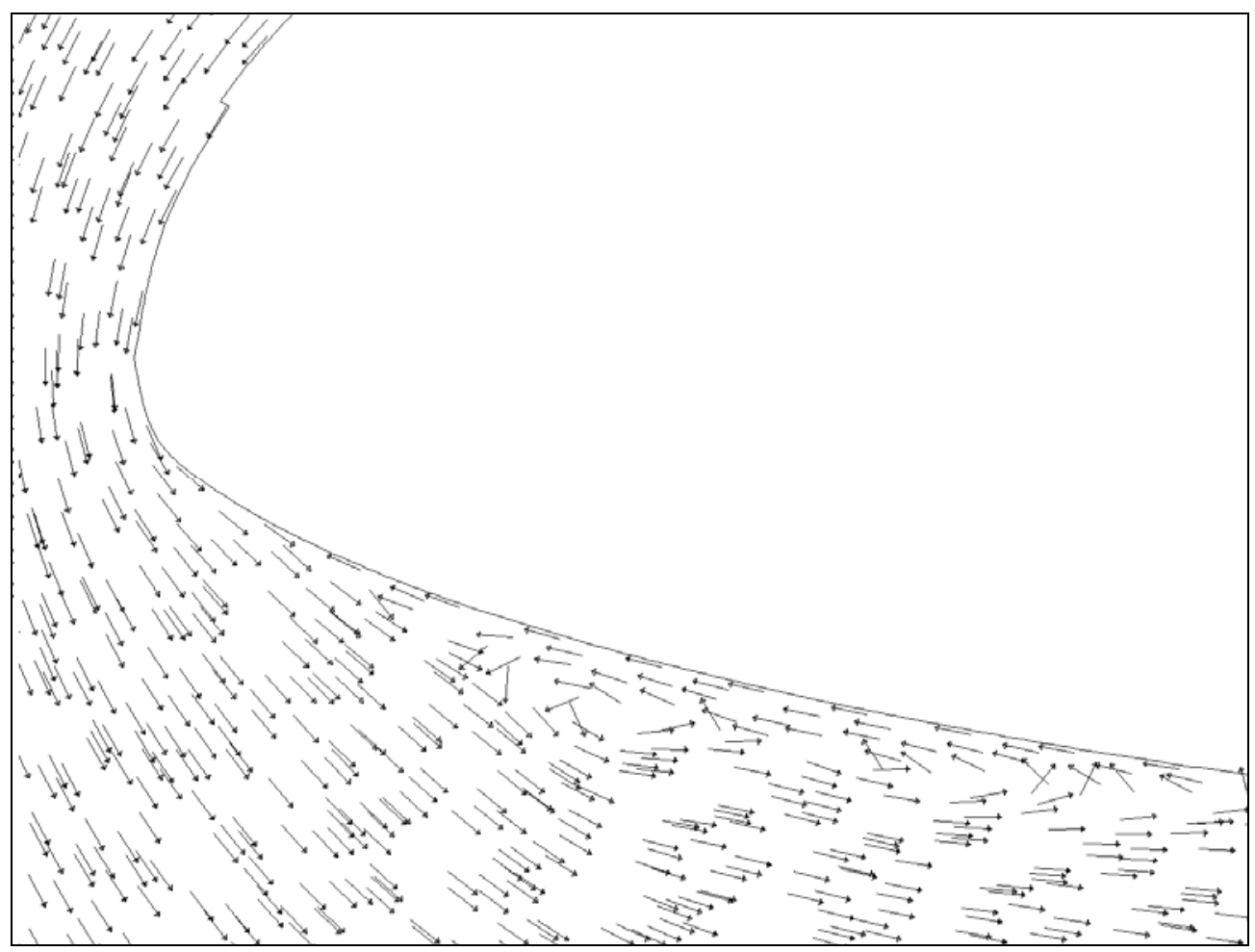

Figure 5.11: Vector Plot near the Leading Edge

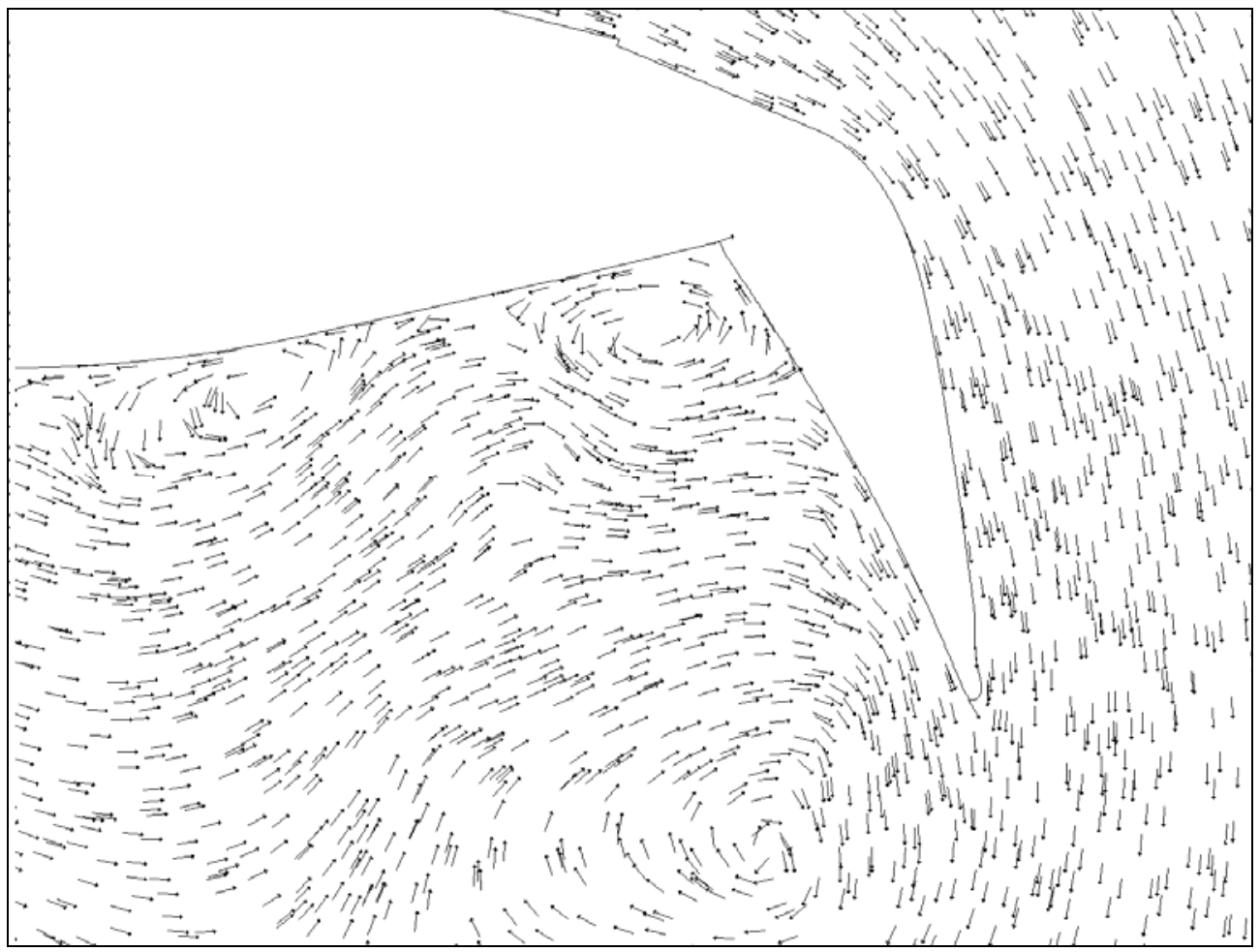

Figure 5.12: Vector Plot near the Trailing Edge 


\section{2c Download Reduction}

Given the proper reference values including depth, characteristic length, velocity, and density, Fluent 6.1 can calculate the forces acting on the airfoil. These forces were comparable to data presented by Riba, 2003 [20].

Figure 5.13 shows the download that was computed for the experimental and computational results. A similar trend is shown in the graph. The percent difference in the two sets of data is roughly 24 percent. The computational results were all computed at sea level standard atmospheric conditions while the experimental results were done in Morgantown, WV, at an elevation of 1,240 ft. Despite this difference, the amount of download when compared to the baseline tests, i.e. percent download reduction, for each approach are very similar as shown in Figure 5.14. The approximate difference in these results is around 3 percent. The comparison in percent reduction is less dependant on the actual forces on the wing so, for this case, Figure 5.14 is a good indication of how the computational tests compare with the experiments.

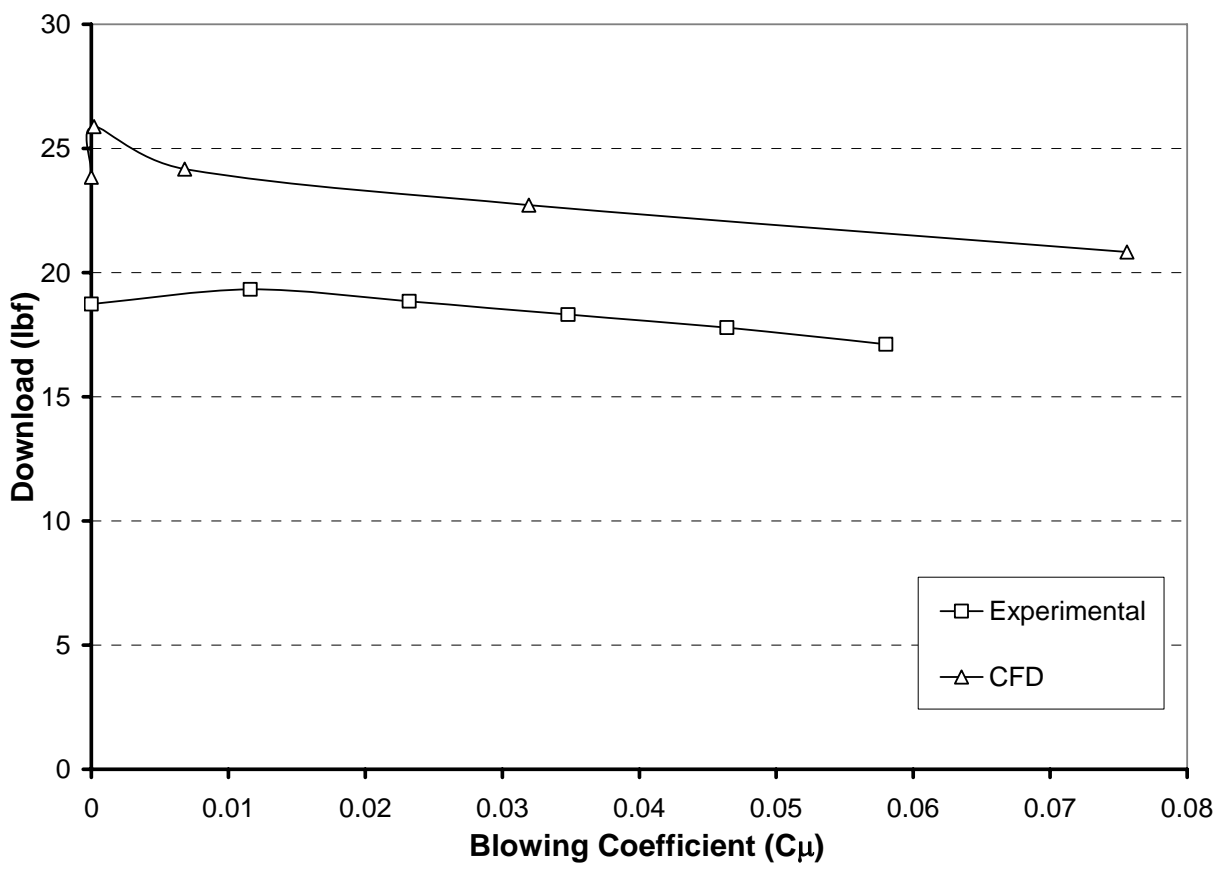

Figure 5.13: Comparison of Download between Experimental and Computational Techniques 


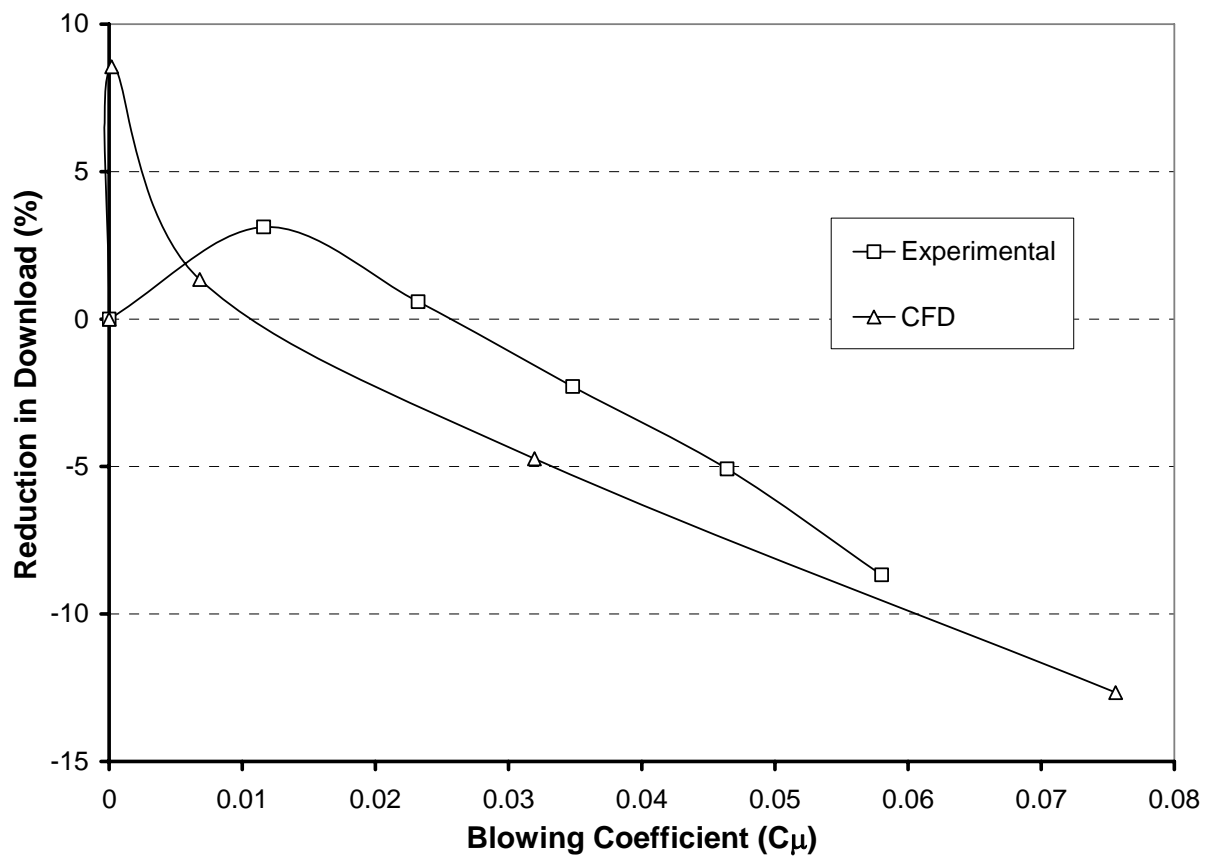

Figure 5.14: Comparison of the Percent Download Reduction between Experimental and Computational Techniques 


\section{Chapter 6.0: Conclusions and Recommendations}

This section draws upon the CFD results to make overall conclusions on the research. The rest of the section makes recommendations for further investigation of blowing slots in CFD.

\subsection{NASA Experiment}

The results from the Felker experiment were used to judge how well the turbulence model worked. As seen in Figure 5.1, extremely good correlation was found between the computational and experimental static pressures at 0.45 radii, with the exception of the leading edge. The position of 0.45 radii has the most agreement with the computational model because this is where the strongest downwash was found during the experiment. Downwash from the rotor drops off significantly further away from the axis of rotation. While actual downwash velocities were not known for the experiment, the chosen speed of 100 fps worked very well. So, using the actuator disk theory along with the Figure of Merit turned out to be a good way to predict downwash velocities immediately downstream of the rotor.

The difference between the static pressures for the upper surface leading edge could be for a few reasons. Originally a grid was created that did not have the wing's leading edge rotated five degrees toward the rotor, like in the experiment. A similar difference was noticed on the leading edge. It was thought that rotating the wing to match the experiment would fix this problem. A new grid was created with five degrees of rotation but very similar results were obtained. In fact, rotating the wing had very little effect on the results. 
Differences could be accounted for by other reasons. The most likely reason is the rotation of the rotor. In the experiment, the rotor sweeps across the wing from the leading edge to the trailing edge. This creates turbulence, swirling, and most likely an average downwash angle that is not normal to the rotor. Since the downwash was approximated as a constant velocity inlet, the results from the computational model could definitely show differences on the leading edge.

Another possible explanation for the differences could be due to computational grid. The data that was used to create the airfoil in the grid seemed to create accurate geometry, except the leading edge had a bit of a sharp point to it. This is most likely not a large source of error. The airflow around the leading edge seemed to flow around this point just as it would a smoothly rounded edge. The sharp edge didn't produce any drastic change in the flow, such as a separation point, but it probably still served as a transitional point toward turbulence. This is also not a large source on concern since that point of the leading edge should serve as a transitional point anyway. A plot of the velocity vectors at the leading edge is presented in Figure 6.1. The wing geometry was created using the data in Tables A.3 through A.5.

All in all, the computational model did a very good job of simulating the experimental data considering the limitations given to it by the simplified conditions. 


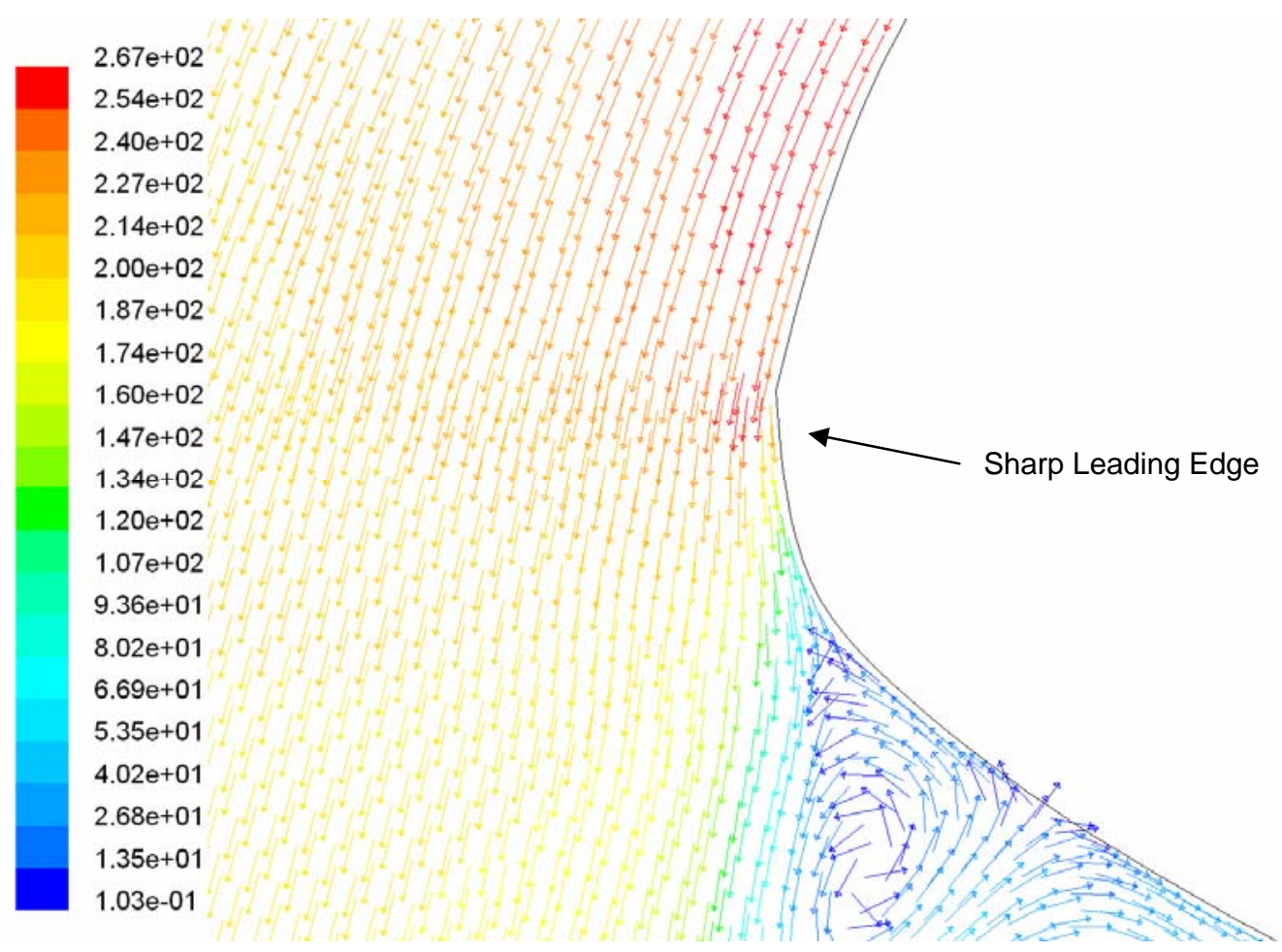

Figure 6.1: Leading Edge Velocity Vectors for NASA Experiment (fps)

\subsection{WVU Experiment}

The airflow around the airfoil seemed to be realistic especially with respect to circulation control. There was notable concern as to how physical the results could be since the grid was under refined near the blowing slots when compared to similar CFD simulations. Even with a $\mathrm{y}^{+}$value that was higher than the normal recommended values, the simulation performed well. This is possibly because the blowing slots were simplified as velocity inlets with steady uniform outflow. Another possibility could stem from the enhanced wall treatment options available in Fluent 6.1. When the $\mathrm{y}^{+}$values are higher than the recommended values, Fluent 6.1 uses wall functions to simulate the flow near the wall. In any case, conclusive evidence that the modeling worked well was obtained through visualization of the flow field and comparison to the WVU experiment. 
The separation points that were displayed in Figure 5.2 show movement of the separation point based on blowing slot coefficient. However, the accuracy to which this figure pinpoints the exact location of separation is subject to error. Since the grid has a finite number of points, the separation point is only as accurate as the grid resolution. Some of the separation points are very close to one another, specifically points one and four. This closeness could be on the order of the size of the grid spacing. So, differences between the two points is hard to discern.

The comparison of the download and the percent download reduction between the computational and experiment results showed similar trends. The differences in the values for the download forces can be accounted for in a few different ways. First of all, the air pressure, density, and temperature were not the same for both the experimental and computational models. The experimental results were done at 1,240 ft in Morgantown, WV, while the computational model used standard atmospheric conditions at sea level. The computational results also did not account for spanwise differences in the flow. Instead, the 2-D model was given a depth of $19 \mathrm{in}$. and the download was calculated using the same flow field over the entire $19 \mathrm{in}$. span. This is clearly a source of error since there could be swirling near the wing tips and the blowing slot may not produce a uniform sheet of air. The blowing slot coefficients that were used from the experiment could also be a source of error. The exact blowing slot velocity was not known for the experiment so blowing slot coefficients were used for comparison. Converting the velocities to blowing slot coefficients provided an additional source of error along with the possibility of non-uniform airflow out of the experimental slots. The computational domain used zero gauge pressure at the pressure outlet. This is true for an 
ideal case, but not in the experimental test section. Also the ambient turbulence present in the WVU wind tunnel was not simulated. This is yet another source of error and could change some of the flow characteristics in the numerical model. All of these possible sources of error could contribute to the differences between the experimental and computational downloads.

\subsection{Recommendations}

While the computational results correlated well to the experimental results, further refinement of the computational grid is still recommended. Extra grid points need to be placed near the blowing slots to resolve all of the viscous sublayer. The viscous sublayer can be fully resolved when the $\mathrm{y}^{+}$value is on the order of one. The grid could also be coarsened further away from the airfoil, especially upstream of the airfoil, to save on computational expenses. A three-dimensional grid could also be useful. This would allow the turbulence, which is inherently three-dimensional, to be modeled more accurately. Also, any spanwise differences in the flow could be used to more correctly calculate the drag based on the downwash.

To help further match the experimental and computational models it would be helpful to match the air properties. This would definitely help to lower the drag experienced by the computational airfoil since it was modeled at a lower altitude. Along with the standard air properties such as temperature, density, and pressure, the turbulence intensity that is within the wind tunnel should be matched. A non-uniform inlet velocity profile could also help to match the experiment to the model. An unsteady solution could also give more insight into what types of flow structures form downstream. The vortices 
that form just off the trailing edge of the flap could very well be unsteady. Time averaging could reduce some of the error in the results.

While the purpose of this research was to match experimental results, further research could be done concerning the performance of the blowing slots. An optimum position for the blowing slots needs to be investigated. This could include moving the blowing slots position, changing the blowing slot height, or even only using one blowing slot. Because of the large low pressure region that is already created near the flap cove region and the fixed position of the separation point on the flap it may be more practical to only use the leading edge blowing slot. Using periodic blowing could also be a way to increase the blowing slot efficiency and it is highly suggested for further research. 


\section{Chapter 7.0: References}

1. Felker, F. Fort, Shinoda, P.R., Heffernan, R.M., Sheehy, H.F., "Wing Force and Surface Pressure Data from a Hover Test of a 0.658-Scale V-22 Rotor and Wing," NASA Technical memorandum 102244, February 1990.

2. Angle, G. M., Riba, C.A., Huebsch, W.W., Thompson, G.J., Smith, J.E., "Downwash Rake Reduction Investigation for Application on the V-22 Osprey," SAE Technical Paper Series 2003-01-3020, September 2003.

3. Schlichting, Herman, Boundary Layer Theory, Pergamon Press, New York, 1955.

4. Churchill, R. A., "Coanda Effect Jet around a Cylinder with an Interacting Adjacent Surface," Ph.D. Dissertation, West Virginia University, Morgantown, WV, 1992.

5. Chang, P. A. III, Slomski, J. F., Marino, T.A., Ebert, M.P., "Numerical Simulation of Two- and Three-Dimensional Circulation Control Problems" AIAA Paper 2005-0080, January 2004.

6. Slomski, J., Marino, T., "Navy Successfully Simulates Effect that May Improve Low-Speed Maneuverability" Journal Articles by Fluent Software Users JA153, 2002.

7. Swanson, R.C., Rumsey, C.L., Anders, S.G., "Progress Towards Computational Method for Circulation Control Airfoils," AIAA Paper 2005-0089, January 2005.

8. Shrewsbury, G. D., "Numerical Evaluation of Circulation Control Airfoil Performance using Navier-Stokes Methods," AIAA Paper 86-0286, January 1986.

9. Baker, Warren J., Paterson, Eric G., "Simulation of Steady Circulation Control for the General Aviation Circulation Control (GACC) Wing” NASA-ONR Circulation Control Workshop, March 2004.

10. Gad-el-Hak, M., "Flow Control: The Future," Journal of Aircraft, Vol. 38, No. 3, May-June, 2001.

11. Slomski, J., Marino, T., "Numerical Simulation of Circulation Control Airfoils as Affected by Different Turbulence Models," AIAA Paper 2002-0851, January 2002

12. Walter, R.E., Myer, D.P., Holt, D.J., "Circulation Control by Steady and Pulsed Blowing for a Cambered Elliptical Airfoil," West Virginia University, July, 1972.

13. Cerchie, D., Cullen, L., Goldstein, J., Wygnanski, I., "Some Circulation Control Experiments," Proceedings of the 2004 NASA/ONR Circulation Control Workshop NASA/CP-2005-213509/PT1, March 2005. pp 369-390.

14. Loth, J.L., Boasson, M., "Circulation Controlled STOL Wing Optimization," Journal of Aircraft, Vol. 21, No. 2, February, 1984.

15. Ferguson, D.J., Franke, M.E., Williams, S.L., "Computational Study of a TwoSlot Circulation Control Airfoil," SAE Technical Paper Series 932531, September 1993.

16. Wu, J., Sanker, L.N., Huff, D., "Evaluation of Three Turbulence Models for the Prediction of Steady and Unsteady Airloads," AIAA Paper 89-0609, January 1989.

17. Felker, F. F., "Wing Download Results from a Test of a 0.658-Scale V-22 Rotor and Wing," Journal of the American Helicopter Society, 1992. pp 58-63. 
18. Angle, G., Huebsch, W.W., Thompson, G., Smith, J., "Experimental and Computational Investigation into the use of the Coanda Effect on the Bell A821201 Airfoil," NASA CP-2005-213509, Part 2.

19. Fluent 6.2 User's Guide, Fluent Inc., 2005-01-04.

20. Rajagopalan, G., "http://www.public.iastate.edu/ aero442/unit2.pdf," Iowa State University, 2002.

21. Riba, C. A., "Circulation Control for Download Wake Reduction in the V-22 Aircraft," Master's Thesis, West Virginia University, Morgantown, WV, 2003. 


\section{Appendix A: NASA Experiment}

Table A.1: Coordinates of Main Wing at 0.658-Scale (in)

\begin{tabular}{|c|c|c|c|}
\hline \multicolumn{4}{|c|}{ Main Wing } \\
\hline \multicolumn{2}{|c|}{ Upper Surface } & \multicolumn{2}{|c|}{ Lower Surface } \\
\hline$x$ & $\bar{Y}$ & $x$ & $\bar{Y}$ \\
\hline 0.0000000 & 0.0000000 & 0.0000000 & 0.0000000 \\
\hline 0.3288000 & 1.4598720 & 0.3288000 & -0.9995520 \\
\hline 0.6576000 & 2.1635040 & 0.6576000 & -1.3020480 \\
\hline 1.3152000 & 3.1696320 & 1.3152000 & -1.7360640 \\
\hline 1.9728000 & 3.9456000 & 1.9728000 & -2.0780160 \\
\hline 2.6304000 & 4.5768960 & 2.6304000 & -2.3673600 \\
\hline 3.2880000 & 5.1161280 & 3.2880000 & -2.6238240 \\
\hline 3.9456000 & 5.5896000 & 3.9456000 & -2.8474080 \\
\hline 5.2608000 & 6.3918720 & 5.2608000 & -3.2419680 \\
\hline 6.5760000 & 7.0428960 & 6.5760000 & -3.5773440 \\
\hline 7.8912000 & 7.5887040 & 7.8912000 & -3.8732640 \\
\hline 9.2064000 & 8.0358720 & 9.2064000 & -4.1297280 \\
\hline 10.5216000 & 8.4172800 & 10.5216000 & -4.3598880 \\
\hline 11.8368000 & 8.7263520 & 11.8368000 & -4.5637440 \\
\hline 13.1520000 & 8.9828160 & 13.1520000 & -4.7412960 \\
\hline 14.4672000 & 9.1932480 & 14.4672000 & -4.8925440 \\
\hline 15.7824000 & 9.3576480 & 15.7824000 & -5.0306400 \\
\hline 17.0976000 & 9.4168320 & 17.0976000 & -5.1490080 \\
\hline 18.4128000 & 9.5746560 & 18.4128000 & -5.2476480 \\
\hline 19.7280000 & 9.6338400 & 19.7280000 & -5.3199840 \\
\hline 23.0160000 & 9.6601440 & 23.0160000 & -5.4383520 \\
\hline 26.3040000 & 9.5286240 & 26.3040000 & -5.4383520 \\
\hline 29.5920000 & 9.2195520 & 29.5920000 & -5.2871040 \\
\hline 32.8800000 & 8.6803200 & 32.8800000 & -4.9385760 \\
\hline 36.1680000 & 7.9240800 & 36.1680000 & -4.3401600 \\
\hline 39.4560000 & 7.1152320 & 39.4560000 & -3.6168000 \\
\hline 42.7440000 & 6.3063840 & 42.7440000 & -2.8868640 \\
\hline 46.4857440 & 5.3923200 & 44.5918560 & -2.4857280 \\
\hline
\end{tabular}


Table A.2: Coordinates of non-rotated Flap at 0.658-Scale (in)

\begin{tabular}{|c|c|c|c|}
\hline \multicolumn{4}{|c|}{ Flap } \\
\hline \multicolumn{2}{|c|}{ Upper Surface } & \multicolumn{2}{|c|}{ Lower Surface } \\
\hline$x$ & $Y$ & $x$ & $Y$ \\
\hline 45.1310880 & 0.5721120 & 45.1310880 & 0.5721120 \\
\hline 45.2 & & 45.2 & -0.0 \\
\hline 45.3 & & 45.3 & \\
\hline 45.7 & & 45. & \\
\hline 46.0 & 2.6 & 46.0 & -1. \\
\hline 46.6 & & & \\
\hline 47.3 & & 47.3 & \\
\hline 48.6 & & 48.6 & \\
\hline 49.9 & & & \\
\hline 51. & & & \\
\hline 52.6 & & & \\
\hline & & & \\
\hline 55.2 & & 5 & -0. \\
\hline 56.5 & & & \\
\hline 59.1 & & & \\
\hline 61.8 & & & -0. \\
\hline 63.1 & & & \\
\hline 64.4 & & & \\
\hline 65.3 & & 65.3 & -0.0065760 \\
\hline 65.3983200 & 0.000 & 65.3983200 & 0.0000000 \\
\hline
\end{tabular}

Table A.3: Coordinates of Flap Cove at 0.658-Scale (in)

Flap Cove

\begin{tabular}{|c|c|}
\hline$X$ & $Y$ \\
\hline 46.4857440 & 5.3923200 \\
\hline 46.0320000 & 4.6952640 \\
\hline 45.3744000 & 3.6825600 \\
\hline 44.7168000 & 2.6698560 \\
\hline 44.0592000 & 1.5519360 \\
\hline 43.6580640 & -0.3288000 \\
\hline 43.8619200 & -1.3283520 \\
\hline 44.0592000 & -1.6900320 \\
\hline 44.5918560 & -2.4857280 \\
\hline
\end{tabular}




\section{Appendix B: WVU Experiment}

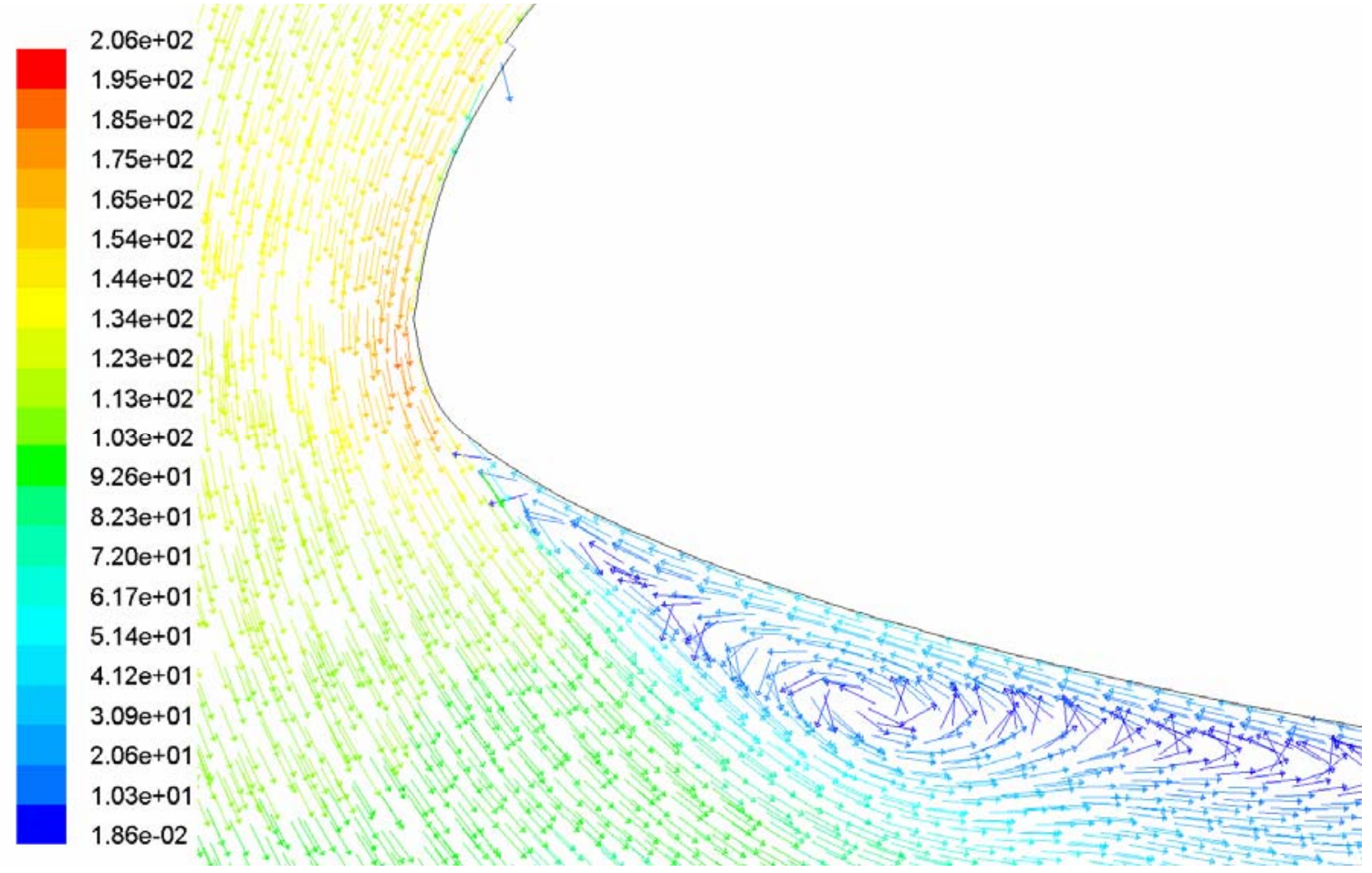

Figure B.1: Leading Edge Blowing Slot Velocity Vectors (fps), Blowing Slot Velocity: 10 fps

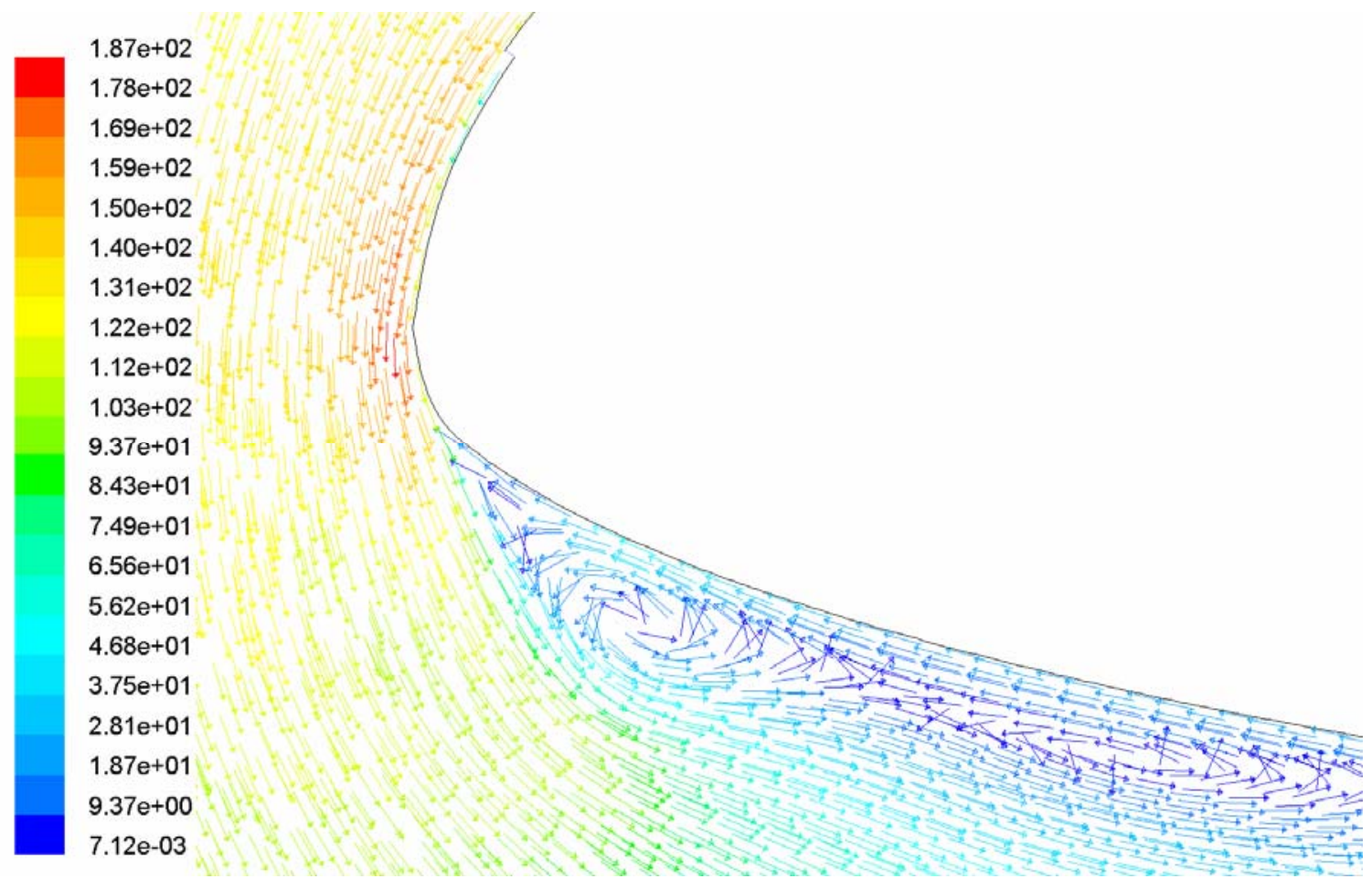

Figure B.2: Leading Edge Blowing Slot Velocity Vectors (fps), Blowing Slot Velocity: 60 fps 


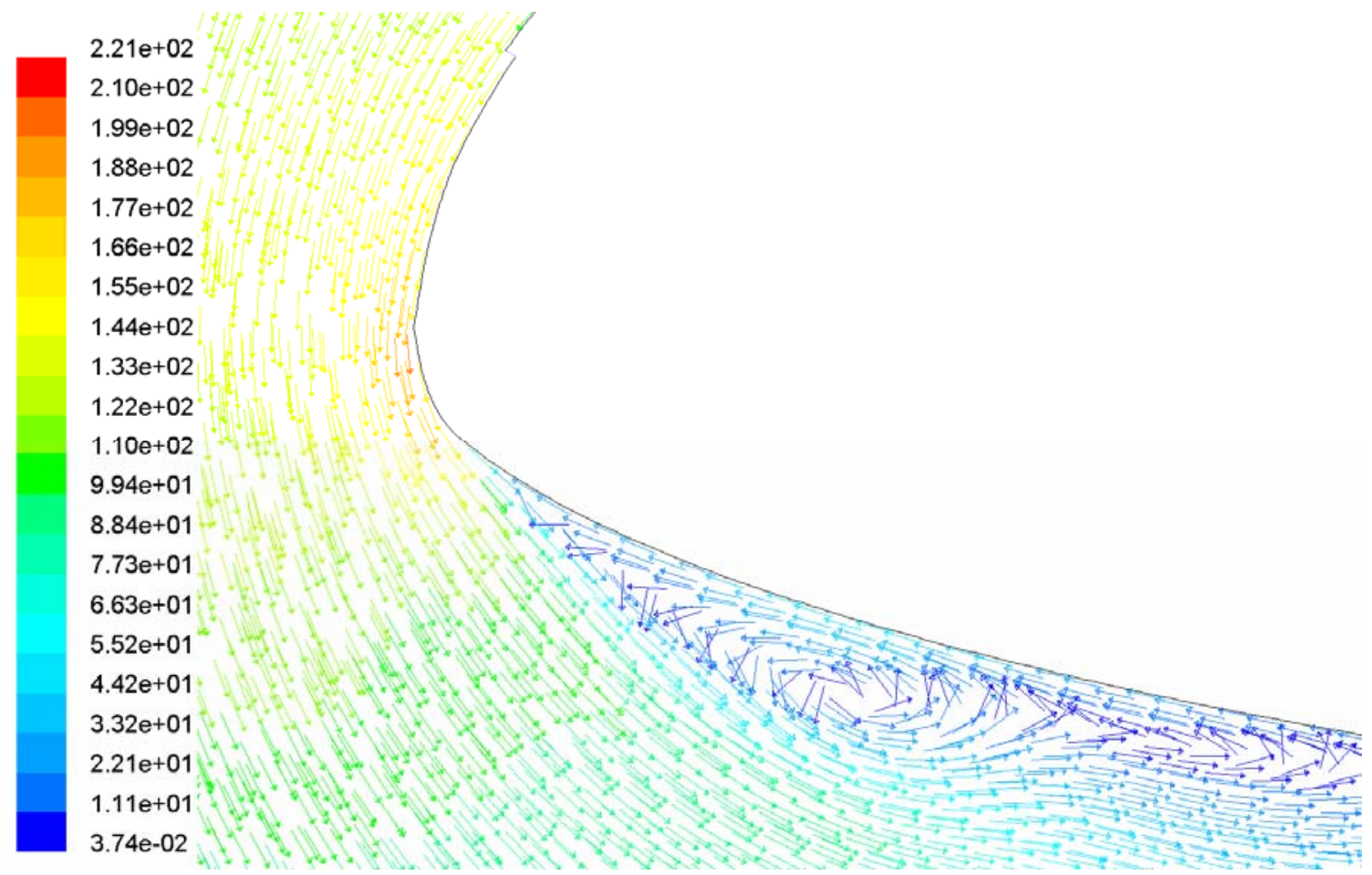

Figure B.3: Leading Edge Blowing Slot Velocity Vectors (fps), Blowing Slot Velocity: 130 fps

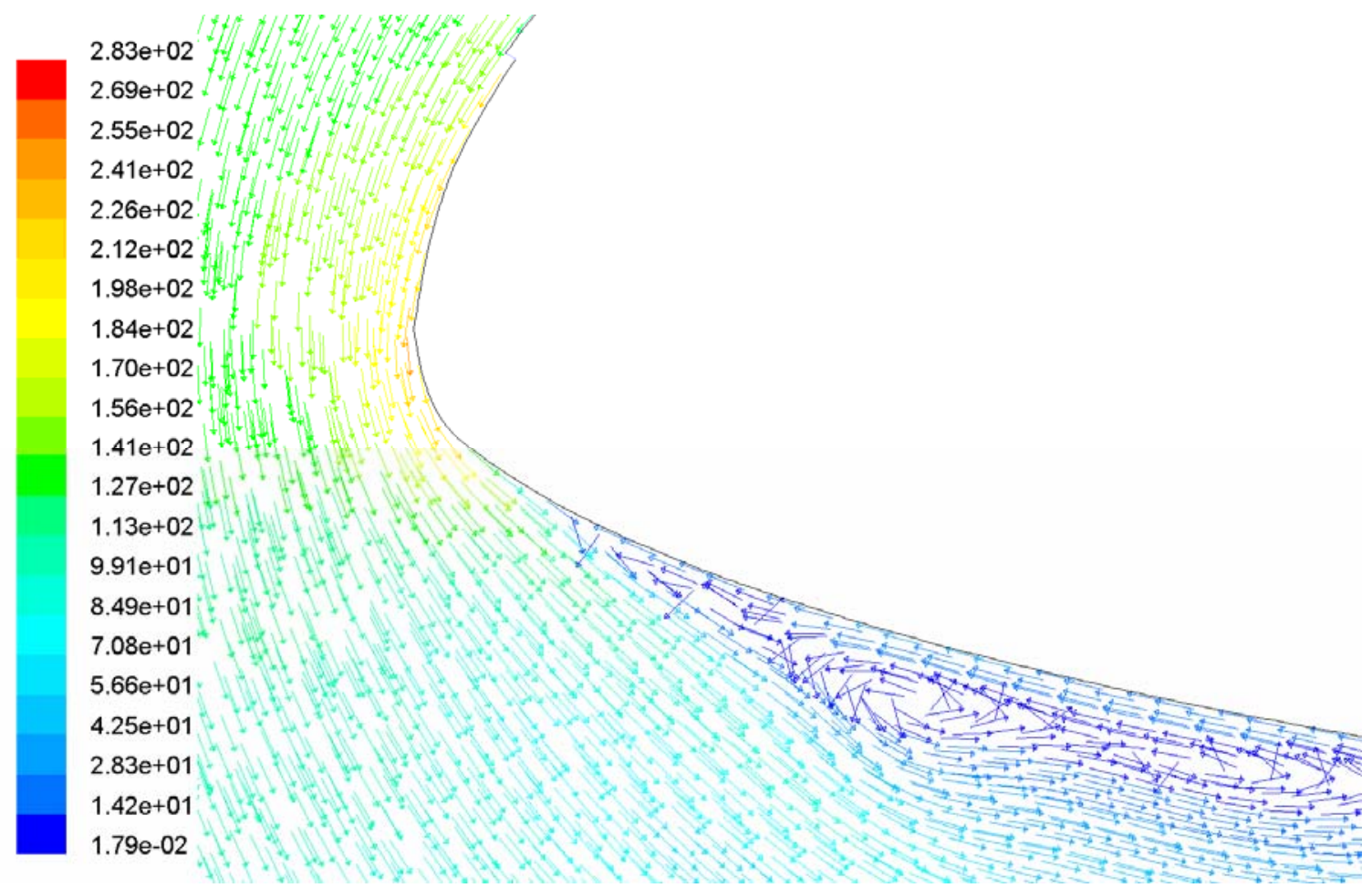

Figure B.4: Leading Edge Blowing Slot Velocity Vectors (fps), Blowing Slot Velocity: 200 fps 


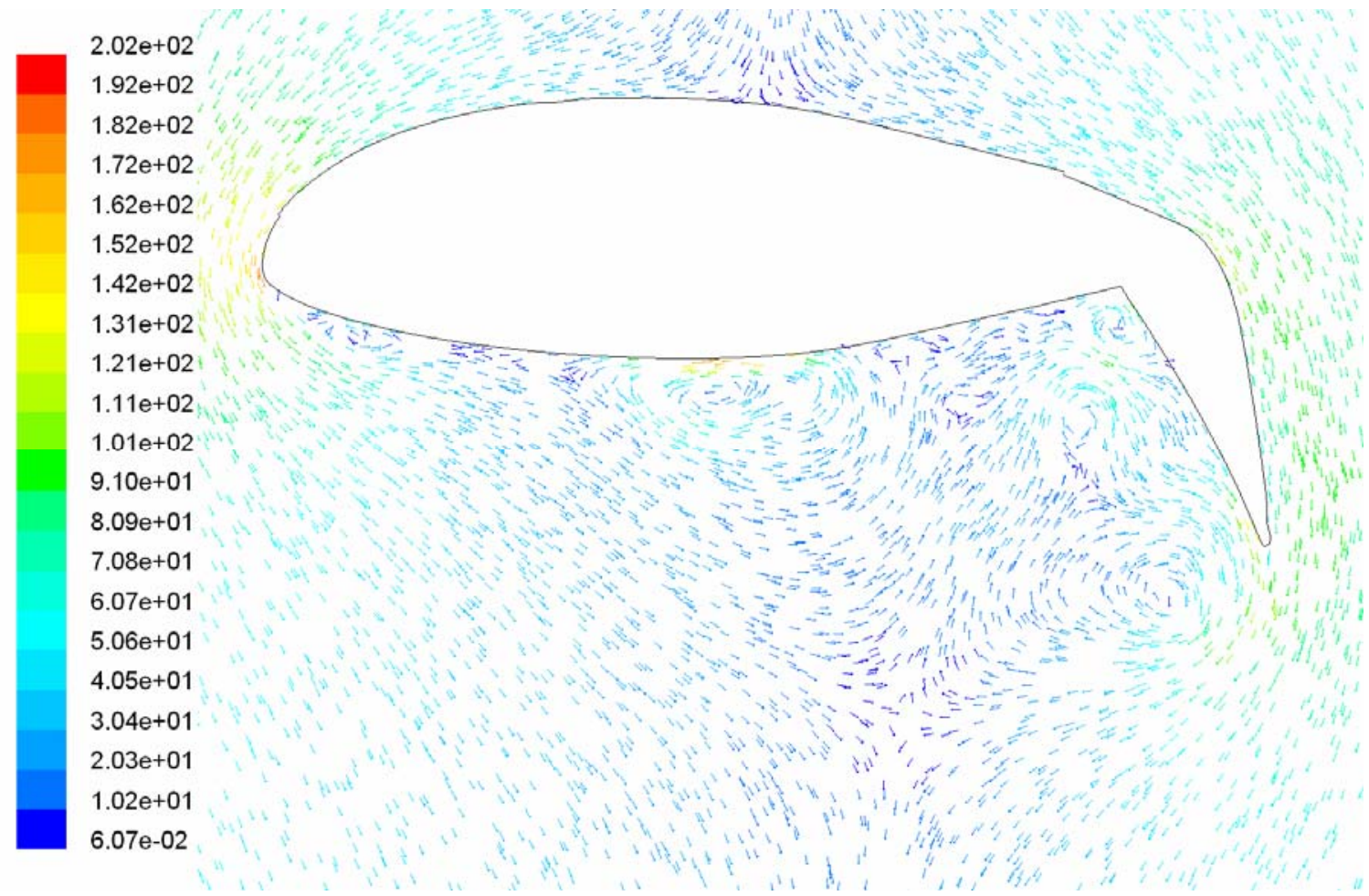

Figure B.5: Velocity Vectors Around Airfoil (fps), Blowing Slot Velocity: 0 fps

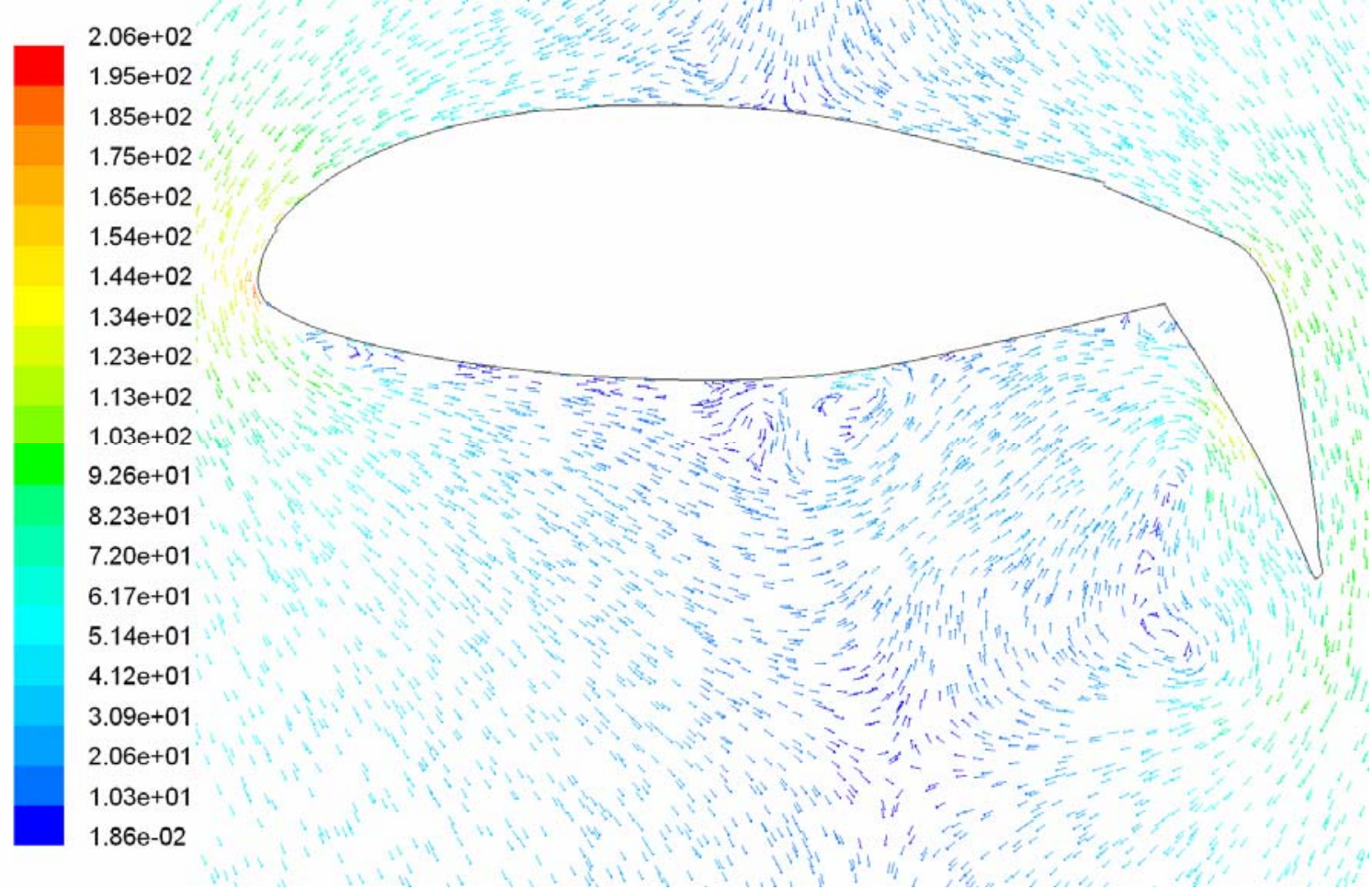

Figure B.6: Velocity Vectors Around Airfoil (fps), Blowing Slot Velocity: 10 fps 


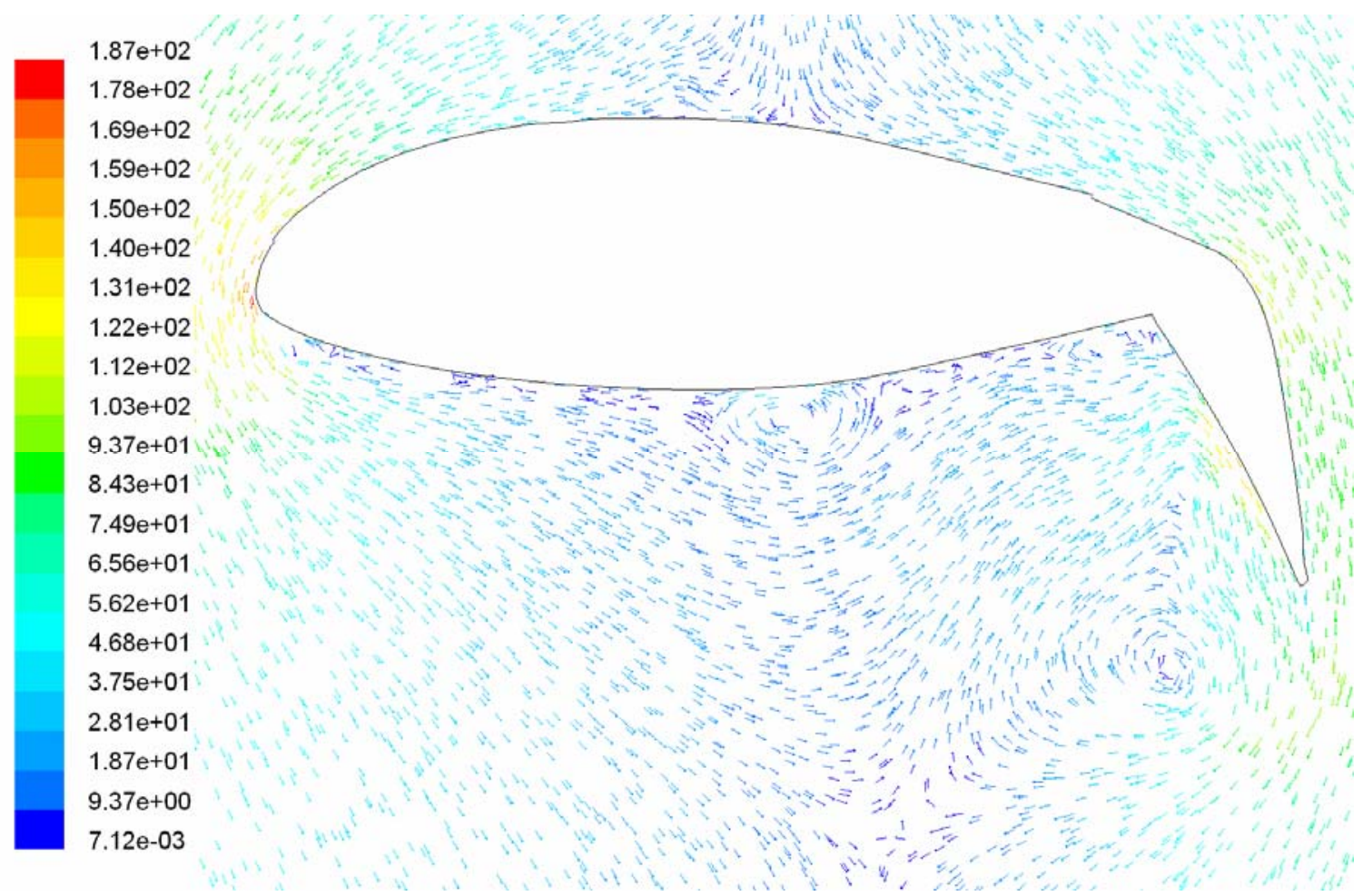

Figure B.7: Velocity Vectors Around Airfoil (fps), Blowing Slot Velocity: 60 fps

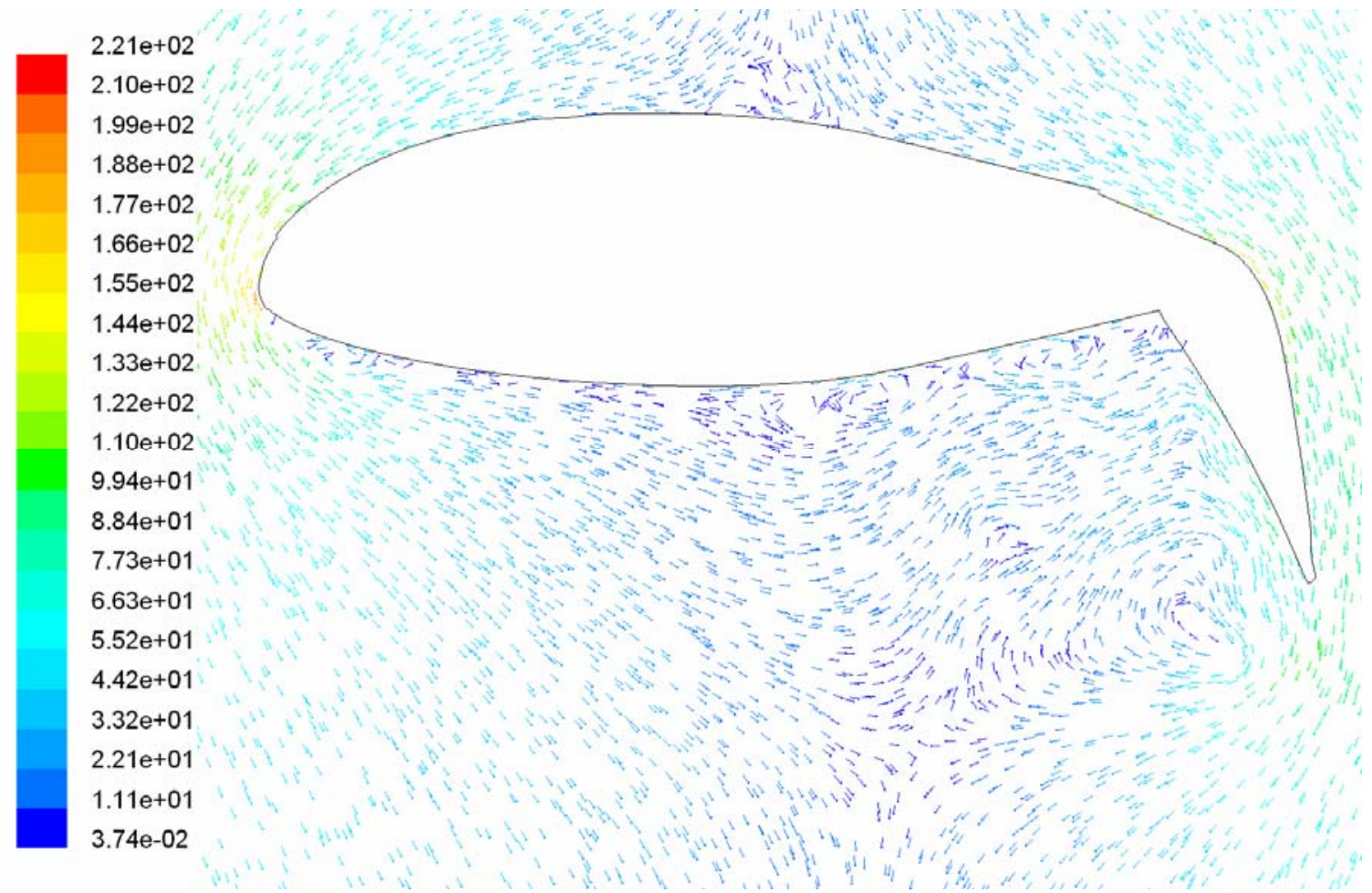

Figure B.8: Velocity Vectors Around Airfoil (fps), Blowing Slot Velocity: 130 fps 


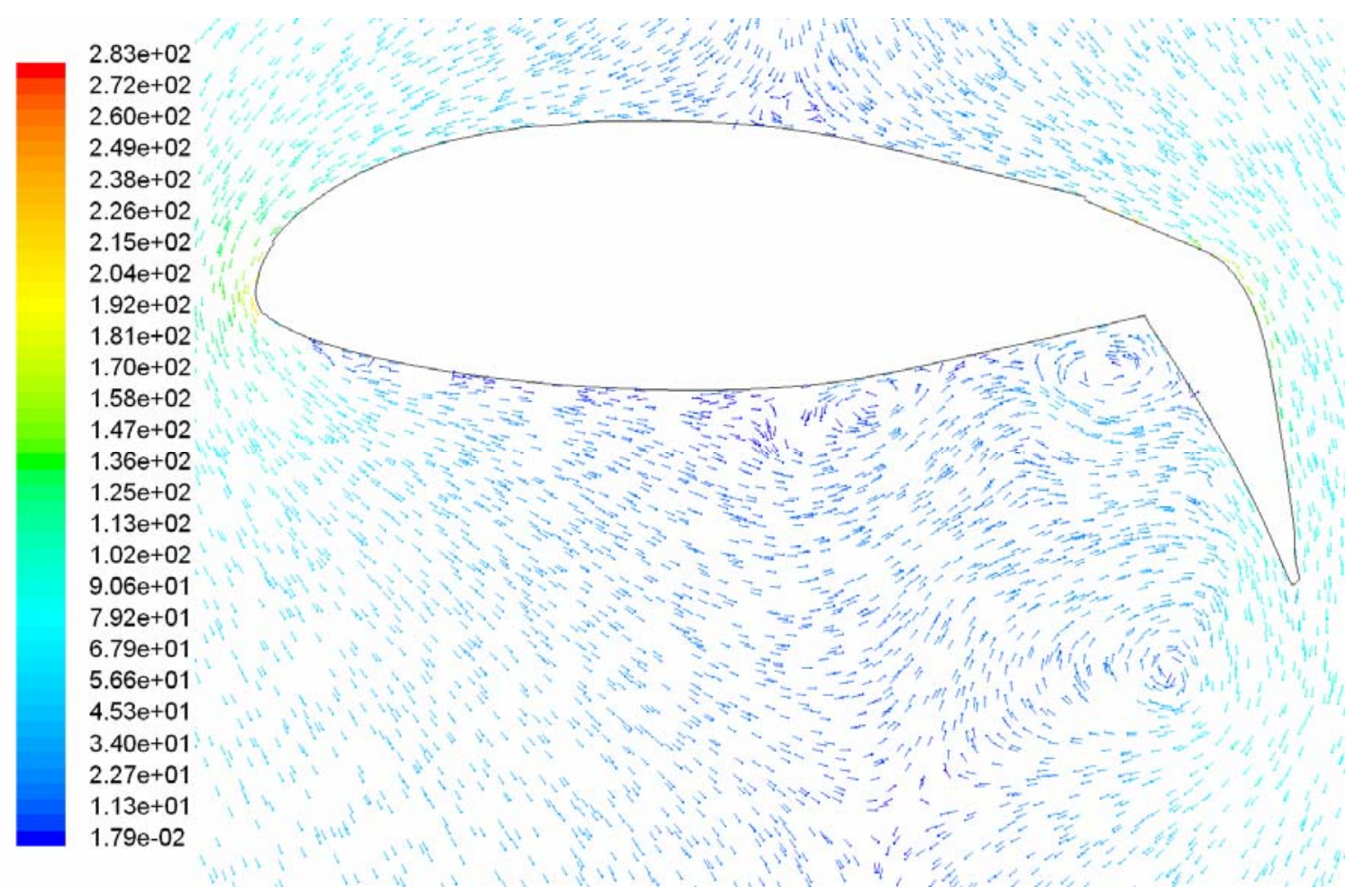

Figure B.9: Velocity Vectors Around Airfoil (fps), Blowing Slot Velocity: 200 fps 